NBER WORKING PAPER SERIES

\title{
EMPIRICAL INVESTIGATION OF A SUFFICIENT STATISTIC FOR MONETARY SHOCKS
}

\author{
Fernando E. Alvarez \\ Andrea Ferrara \\ Erwan Gautier \\ Hervé Le Bihan \\ Francesco Lippi \\ Working Paper 29490 \\ http://www.nber.org/papers/w29490
}

\author{
NATIONAL BUREAU OF ECONOMIC RESEARCH \\ 1050 Massachusetts Avenue \\ Cambridge, MA 02138 \\ November 2021
}

The views expressed in this paper are those of the authors and do not necessarily reflect those of the Banco de España, the Banque de France or the Eurosystem. We thank John Leahy for pushing us to pursue this question in Leahy (2016). We are indebted with Luca Dedola and Klaus Adam, our discussants at the Banque de France seminar and the 2021 Hydra conference for their useful comments. We are grateful to seminar participants at the ECB Prisma meeting (November 2020), the University of Wisconsin, the Einaudi Institute for Economics and Finance, the Bank of Italy, the University of Michigan, the University of Bielefeld, the Imperial College, the University of Edinburgh, the Bank for International Settlements, the IMF, the Banque de France, the Banco de España, the 2021 CEBRA conference, the 2021 Minnesota Workshop in Macroeconomic Theory, the 2021 Hydra Conference. The views expressed herein are those of the authors and do not necessarily reflect the views of the National Bureau of Economic Research.

At least one co-author has disclosed additional relationships of potential relevance for this research. Further information is available online at http://www.nber.org/papers/w29490.ack

NBER working papers are circulated for discussion and comment purposes. They have not been peer-reviewed or been subject to the review by the NBER Board of Directors that accompanies official NBER publications.

(C) 2021 by Fernando E. Alvarez, Andrea Ferrara, Erwan Gautier, Hervé Le Bihan, and Francesco Lippi. All rights reserved. Short sections of text, not to exceed two paragraphs, may be quoted without explicit permission provided that full credit, including $\odot$ notice, is given to the source. 
Empirical Investigation of a Sufficient Statistic for Monetary Shocks

Fernando E. Alvarez, Andrea Ferrara, Erwan Gautier, Hervé Le Bihan, and Francesco Lippi

NBER Working Paper No. 29490

November 2021

JEL No. E31,E5

\section{ABSTRACT}

In a broad class of sticky price models the non-neutrality of nominal shocks is encoded by a simple sufficient statistic: the ratio of the kurtosis of the size-distribution of price changes over the frequency of price changes. We test this theoretical prediction using data for a large number of firms representative of the French economy. We use the micro data to measure the cross sectional moments, including kurtosis and frequency, for about 120 PPI industries and 220 CPI categories. We use a Factor Augmented VAR to measure the sectoral responses to a monetary shock, as summarized by the cumulative impulse response of sectoral prices (CIRP), under three alternative identification schemes. The estimated CIRP correlates with the kurtosis and the frequency consistently with the prediction of the theory (i.e. they enter the relationship as a ratio). The analysis also shows that other moments not suggested by the theory, such as the mean, standard deviation and skewness of the size-distribution of price changes, are not correlated with the CIR . Several robustness checks are discussed.

Fernando E. Alvarez

University of Chicago

Department of Economics

1126 East 59th Street

Chicago, IL 60637

and NBER

f-alvarez1@uchicago.edu

Andrea Ferrara

Northwestern University

andr.ferrara1@gmail.com

Erwan Gautier

Banque de France

31 rue Croix des Petits-Champs

75049 PARIS Cedex 01

France

Erwan.GAUTIER@banque-france.fr
Hervé Le Bihan

Banque de France

and Banco de España

herve.lebihan@banque-france.fr

Francesco Lippi

Luiss University

and EIEF

francescolippi@gmail.com 


\section{Introduction}

Many recent contributions in economics are characterized by the quest for a sufficient-statistic, a theoretical metric that summarizes the effect of a policy using only a few (high-level) parameters leaving aside a large number of modeling details. Chetty (2009) coined the phrase, tracing the origin of the idea to Koopmans (1953), Marschak (1953) and Harberger (1964), and discussed advantages and limitations of using sufficient statistics in public finance models. Summarizing the workings of complex models with a few measurable elasticities is convenient, useful for model selection and holds promise for policy analysis. Several papers in public finance and international trade have successfully followed the approach. ${ }^{1}$

In the area of monetary economics recent results have identified a sufficient statistic for monetary shocks for a broad class of sticky-price models under low inflation. The key proposition is that the cumulative response of output to a once-and-for-all small monetary shock, essentially the area under the output impulse response, is proportional to the ratio of the kurtosis of the steady-state distribution of price changes over the frequency of price changes. A version of this theoretical result was first established in Alvarez, Le Bihan, and Lippi (2016) for the sticky price model of Nakamura and Steinsson (2010), that nests as special cases two workhorse of macroeconomics: Calvo (1983) and Golosov and Lucas (2007). The result was extended by Alvarez, Lippi, and Oskolkov (2021) to a broader class of state-dependent models using the generalized hazard function setup of Caballero and Engel (1993, 1999). ${ }^{2}$ Alvarez, Lippi, and Paciello (2016) showed the same sufficient statistic to hold in models where firms follow time-dependent rules as in the seminal work of Reis (2006). Given the multitude of theoretical setups that produce this prediction, Leahy (2016) considered the empirical test of the sufficient-statistic proposition a priority for this research program. ${ }^{3}$

\footnotetext{
${ }^{1}$ Examples include Schmieder and von Wachter (2016); Badel and Huggett (2017); Kleven (2020) for an extension of Chetty's formula in the field of public finance with empirical applications, see Arkolakis, Costinot, and RodriguezClare (2012); Anderson and Neary (2016) for international trade applications, Costinot and Werning (2018) for an application to optimal technology regulation.

${ }^{2}$ This class also includes time-dependent models a la Calvo, canonical menu-cost models a la Golosov-Lucas, intermediate cases such as the Calvo-Plus by Nakamura and Steinsson or inherently random-menu cost models such as those of Caballero and Engel. Moreover, the result holds in multi-product models, and also holds in a class of costly information models that give rise to time-dependent rules, spanning classic models such as Taylor (1980); Caballero (1989); Reis (2006). Additional results are discussed by Baley and Blanco (2021) for a setup with non-negligible drift and by Alexandrov (2020) for the case of large nominal shocks.

${ }^{3}$ In a discussion of these theoretical results John Leahy wrote "I would not expect this equation to fit the data
} 
This paper presents an empirical test of the predictions of the sufficient-statistic proposition using the restrictions implied by the theory for an economy with low inflation. The theoretical prediction is somewhat bold: the ratio of kurtosis to frequency should explain different degrees of monetary non-neutrality, while other moments should not matter (e.g. the variance, or the skewness, of price changes). This paper tests the sufficient-statistic result using producer price indices (PPI) and consumer price indices (CPI) micro data for a large number of firms that are representative of the French economy. Our test is made of three steps. We first estimate the sectoral responses to a monetary shock for about 120 PPI industries and 220 CPI categories, using a Factor Augmented VAR in the vein of Bernanke, Boivin, and Eliasz (2005) and Boivin, Giannoni, and Mihov (2009). We identify the monetary shocks using three alternative schemes: two use a recursive ordering (with and without long-run restrictions being imposed), a third one uses highfrequency identification. We summarize the extent of the non-neutrality using the cumulative impulse response of the sectoral prices $\left(C I R^{P}\right)$. As the sufficient statistic proposition concerns the cumulated response of output, we use the theory to derive the testable implications for the cumulated response of prices. This has two advantages: to increase the number of cross-sectoral observations that can be used in the tests, since output data are scarce relative to pricing data, and to map the theoretical prediction into a metric that is more robust. ${ }^{4}$ The second step consists in using the micro data underlying the sectoral data to measure the cross sectional moments of the distribution of price changes in the different sectors. In the third step, we inspect the relationship between the $C I R^{P}$ and the cross-sectoral moments under the restrictions implied by the theory.

The results consistently show that the data do not reject the predictions of the theory across a variety of tests, specifications, and robustness exercises. Both the frequency and the kurtosis appear as statistically significant factors in accounting for the cross-sectional heterogeneity of the estimated $C I R^{P}$ for both the PPI data as well for the CPI data. The sign and magnitudes of the estimated coefficients are consistent with the predictions of the theory in the specification where the variables enter the regression as a ratio, as the theory prescribes, as well as in an unrestricted specification where both variables are entered as separate regressors. Moreover, "placebo" tests perfectly, but it would be very nice to know if these statistics are at all informative. (p. 462)".

\footnotetext{
${ }^{4}$ The output response depends on sector specific elasticities that require additional information for the test.
} 
show that moments not suggested by the theory, such as the size, standard deviation and skewness of price changes, are not correlated with the $C I R^{P}$. In addition, results are robust to allowing in various ways for measurement errors, an important concern when micro price data are used. When we compare results for PPI and CPI products, we find that the results for PPI are more robust than the results for CPI products. In the robustness analysis, we find that when removing products with frequent sales and substitutions (in particular, food, clothing and furniture), the CPI results align more closely with the ones obtained for PPI products. This is consistent with the fact that the model underlying the sufficient statistic result assumes no seasonal sales. It should not be surprising that, given the simplicity of the model and the many measurement issues involved, the variables suggested by the theory explain only a fraction of the cross sectional differences in the non-neutrality. But it is noticeable that, across of broad range of specifications, both kurtosis and frequency are related to non-neutrality in a way that is aligned with theory and that both variables are statistically significant.

At a high level, this paper relates to the voluminous applied literature that analyzes the implications of price-setting patterns, in particular cross sectoral heterogeneity, for the propagation of shocks, e.g. Bils and Klenow (2004); Burstein, Eichenbaum, and Rebelo (2005); Carvalho (2006); Bouakez, Cardia, and Ruge-Murcia (2009); Cavallo and Rigobon (2016); Cavallo (2018, 2019); Amiti, Itskhoki, and Konings (2019); Bonomo, Carvalho, Kryvtsov, Ribon, and Rigato (2020); Carvalho, Lee, and Park (2021); Dedola, Kristøffersen, and Züllig (2021); Auer, Burstein, and Lein (2021). The specific novelty of this paper is to test the sufficient-statistic proposition for monetary shocks, using the restrictions implied by the theoretical model. The theory guides our empirical analysis: it identifies the variables of interest, how they enter the test, and shows how to interpret sign and magnitude of the estimated coefficients. Several previous studies highlighted the importance of the frequency of price changes as a factor behind the cross-sectoral response to an aggregate shock, e.g. Nakamura and Steinsson (2010); Imbs, Jondeau, and Pelgrin (2011); Gorodnichenko and Weber (2016); La'O and Tahbaz-Salehi (2020). The sufficient statistic proposition that we analyze supplements the predictions for the role of frequency with a prediction for the role of kurtosis, which indeed our data confirm to be relevant. Following the same empirical 
strategy as this paper, Gautier, Marx, and Vertier (2021) test the sufficient statistic prediction on gasoline price data for France. They calculate the frequency and kurtosis of price changes at the gas station level, and estimate the $C I R^{P}$ of each gas station to a shock of the gasoline input cost. Their estimates show that the ratio of kurtosis over frequency correlates negatively with $C I R^{P}$ as predicted by the sufficient statistic theory and that both frequency and kurtosis taken separately correlate equally and significantly with $C I R^{P}$ and with the expected sign. ${ }^{5}$

A related analysis is developed by Hong et al. (2020), who inspect the correlation between the response of sectoral producer price indices in the United States and several cross-sectional moments of the distribution of price changes. They document a positive correlation between the price response to monetary shocks and the ratio of kurtosis over frequency as well as frequency alone, but provide mixed evidence on the role of kurtosis, which is entered as the sole regressor in several specifications. The authors' aim is to develop a broad empirical investigation on the determinants of sectoral responses to monetary policy shocks, without focusing on a specific theory behind the empirical analysis. The lack of a tight link between the theory and the empirics prevents such results from providing a rigorous test of the sufficient statistic proposition. ${ }^{6}$

The paper is organized as follows. Section 2 presents the sufficient-statistic proposition for small monetary shocks and derives the theoretical restrictions to be tested on the data. Section 3 uses micro and sectoral data to measure the key ingredients needed to test the theory: (i) the sectoral response of prices and output to monetary shocks (ii) candidate sufficient statistics, i.e. several cross-sectoral micro moments. Section 4 presents the baseline results of the tests using cross sectional data. Section 5 investigates the robustness of our findings using a number of alternative measures and specifications. Section 6 concludes and discusses avenues for future research.

\footnotetext{
${ }^{5}$ The analysis of Gautier, Marx, and Vertier (2021) has three main advantages over ours: first, the good is very homogenous and each gas station has a long time series (relative to the frequency of price changes and to the half-life of the impulse response). Second, prices have almost no measurement error. Third, the cost shocks are arguably exogenous and display high frequency variation. As a consequence, the analysis is conducted at the level of each gas station and hence allows for arbitrary heterogeneity across price setters. The results are precisely estimated and highly supportive of the predictions of the sufficient statistic result for the case without strategic complementarity. The disadvantage, relative to our analysis, is that the results only apply to a particular industry.

${ }^{6}$ In the specifications where kurtosis and frequency are both entered as regressors the signs of the estimated coefficients are actually consistent with the sufficient statistic proposition. See e.g. columns 9 to 13 in Table 2 in Hong et al. (2020), or the cross sectional regressions of Table 16 where both kurtosis and frequency are statistically significant and with the expected signs (especially so when fixed effects are not used).
} 


\section{A Sufficient Statistic for Monetary Shocks}

This section presents the sufficient-statistic proposition for monetary shocks and derives some empirically testable implications. We first, in Section 2.1, illustrate the theory using Caballero and Engel's (1999) model, because of the generality of this setup that encompasses a vast class of sticky-price models. We then, in Section 2.2, state the sufficient statistic result, highlight the assumptions that are important for the result to hold, discuss other setups where the result applies and setups where the result does not hold. Finally we derive various empirical tests for the theory (Section 2.3).

\subsection{Set-up: a Structural Model of Price Stickiness}

We consider an economy populated by a continuum of firms and a representative consumer. The firms are ex ante identical and are hit by idiosyncratic shocks. We consider the price setting problem for a firm in steady state using the random menu cost model of Caballero and Engel (1999) and Caballero and Engel (2007), which covers a vast class of sticky-price models, including several well known cases such as the canonical Golosov and Lucas (2007), the pure Calvo (1983) model and the hybrid Calvo-Plus model by Nakamura and Steinsson (2010).

The setup considers a firm whose marginal nominal cost follows a Brownian motion with variance $\sigma^{2}$ and drift $\mu$, where the latter is due to inflation. The full model is taken from Alvarez, Lippi, and Oskolkov (2021), a summary is given in Appendix A. The state of the firm $x$ is given by its "price gap", defined as the price currently charged by the firm relative to the price that maximizes current profits, which is proportional to the firm cost (measured as the log of the ratio between these prices). In the absence of control the price gap evolves as $d x=\mu d t+\sigma d W$ where $W$ is a standard Brownian motion. At any moment the firm can change its price, and thus control $x$, by paying the menu cost $\Psi>0$. Moreover, with probability $\kappa$ per unit of time, the firm receives an opportunity to pay a menu cost $\psi \in[0, \Psi)$ drawn from the distribution $G(\psi)$. The distribution is allowed to have countably many mass points. We also allow for $\Psi$ to diverge. For instance a distribution with a mass point at $\psi=0$ and $\Psi \rightarrow \infty$ can be used to generate the Calvo model. When the distribution $G$ is not degenerate the adjustment costs are random, which is why 
these models are often referred to as to "random menu cost" models. The firm maximizes the expected discounted value of profits and chooses the optimal times and size of price adjustment as a function of its state $x$. The firm's optimal choices are encoded in the minimized value function $v(x)$, described in the appendix, which defines the optimal return point $x^{*}=\arg \min _{z} v(z)$, namely the optimal price gap chosen by a firm that adjusts. The value function also defines the optimal boundaries of the inaction region $\underline{X}<\bar{X}$ which satisfy the smooth-pasting and value matching conditions described in the appendix.

Policy Rules. Following Caballero and Engel (1999) the optimal policy can be summarized by a generalized hazard function, $\Lambda:(\underline{X}, \bar{X}) \rightarrow \mathbb{R}_{+}$, which gives the probability (per unit of time) that a firm with $x \in(\underline{X}, \bar{X})$ will change its price. The generalized hazard function is defined by the optimal decision rule, or the value function, as well the Poisson arrival rate $\kappa>0$ and the distribution of fixed cost $G$. Formally, the generalized hazard function satisfies ${ }^{7}$

$$
\Lambda(x)=\kappa G\left(v(x)-v\left(x^{*}\right)\right) \text { for all } x \in(\underline{X}, \bar{X})
$$

Intuitively, the probability of adjustment at $x$ is given by the fraction of firms that draw a menu cost that is smaller than the benefit of adjusting. The value function $v(\cdot)$ and the generalized hazard function $\Lambda(\cdot)$ have a minimum at $x^{*}$, are decreasing in $x$ for $x \in\left(\underline{X}, x^{*}\right)$, and increasing in $x$ for $x \in\left(x^{*}, \bar{X}\right)$.

Compared to the workhorse Calvo (1983) model, where the adjustment probability is constant, a generalized hazard function $\Lambda(x)$ allows it to depend on the state $x$, the firm's desired adjustment. Such state dependence is appealing theoretically, see e.g. Barro (1972); Sheshinski and Weiss (1977); Dixit (1991); Golosov and Lucas (2007), and has been found to be relevant empirically, see e.g. Fougere, Le Bihan, and Sevestre (2007); Dias, Marques, and Santos Silva (2007); Eichenbaum, Jaimovich, and Rebelo (2011); Gautier and Le Saout (2015). ${ }^{8}$ A large number of models are nested

\footnotetext{
${ }^{7}$ This is the continuous time version of equation (8) in Caballero and Engel (1999) discrete time model where the draws from the distribution $G$ occur in every period.

${ }^{8}$ Several authors have employed the generalized hazard function in applications and empirical work. For recent applications see e.g. Costain and Nakov (2011); Carvalho and Kryvtsov (2018); Sheremirov (2019); for empirical work see e.g. Berger and Vavra (2018); Petrella, Santoro, and de la Porte Simonsen (2018), and for related theoretical work Baley and Blanco (2021).
} 
by this framework, including the canonical Calvo model with a constant hazard $\Lambda(x)=\lambda$, the Golosov and Lucas (2007) model with $x$ bounded by the adjustment thresholds where the hazard equals zero for $x \in(\underline{X}, \bar{X})$ and spikes at the adjustment thresholds. Intermediate cases cover the so called Calvo-Plus model by Nakamura and Steinsson (2010), the random menu cost problem of Dotsey and Wolman (2020).

Mapping the Model to Observables. Absent aggregate shocks the model is characterized by an invariant distribution of price gaps with density $f(\cdot):(\underline{X}, \bar{X}) \rightarrow \mathbb{R}_{+}$. As shown in Appendix A, the distribution $f(x)$ is uniquely determined by the generalized hazard function $\Lambda(x)$.

The functions $f$ and $\Lambda$ are used to compute several steady-state objects that are observable in the data, such as the frequency of price adjustments $N(\mu)$, and the distribution of the size of price changes $c, Q(c ; \mu)$, where the notation emphasises the dependence of these moments on the rate of inflation (equal to $-\mu$ ). In turn, the latter is used to compute moments such as the variance of price changes, $\operatorname{Var}(\mu)$, and the Kurtosis, $\operatorname{Kurt}(\mu)$.

Statistics for Low Inflation Economies. The main theoretical result that we present below will be established for economies where inflation is zero, i.e. $\mu=0$. In this case the decision rules are symmetric, in the sense that $\bar{X}=-\underline{X}$, and the optimal return point is $x^{*}=0$, located in the middle of the inaction region. Hence price changes are such that, upon adjustment, a firm with a price gap $x$ chooses to "close the gap" completely, i.e. it chooses a price change $c=-x$ to reset the state at $x^{*}=0$. The hazard function $\Lambda$, the invariant density $f$, and the size distribution of price changes $Q$ are also symmetric around zero.

We will argue that the result for zero inflation provides an accurate approximation for economies where inflation is small, but not zero. The reason for this claim is that in models with idiosyncratic shocks (formally where $\mu / \sigma^{2}<\infty$ ) the variables of interest, such as the frequency, the kurtosis and the variance of price changes, all exhibit a zero elasticity with respect to inflation when evaluated 
at zero inflation. Formally, it can be shown that ${ }^{9}$

$$
\left.\frac{\partial N(\mu)}{\partial \mu}\right|_{\mu=0}=\left.\frac{\partial \operatorname{Var}(\mu)}{\partial \mu}\right|_{\mu=0}=\left.\frac{\partial \operatorname{Kurt}(\mu)}{\partial \mu}\right|_{\mu=0}=0
$$

Intuitively, this result states that the values of the even moments, such as frequency of price adjustment, variance or kurtosis, change very little when we move from zero to small inflation rates. Alvarez, Beraja, Gonzalez-Rozada, and Neumeyer (2019) offer new empirical evidence to validate this prediction.

\subsection{The Sufficient Statistic Result}

Next, we discuss the propagation of a monetary shock in this economy. In particular, we consider an economy in steady state, ie, with an invariant cross-sectional distribution of price gaps $f(x)$, and analyze the effect of an unexpected once-and-for-all monetary shock of size $\delta>0$ on output. We consider the impulse response of output to such a shock, and focus on the area below such impulse response, named $C I R^{Y}$ as in Cumulated Impulse Response, as a summary measure of the propagation mechanism.

Analytical results on the computation of the $C I R^{Y}$ have been developed in recent papers focusing on small shocks and zero inflation by Alvarez, Le Bihan, and Lippi (2016); Alvarez, Lippi, and Paciello (2016). More results for environment with non-zero inflation and small shocks have been developed by Alvarez, Lippi, and Oskolkov (2021); Baley and Blanco (2021); analytical results for large shocks in the presence of non-negligible inflation are studied in Alexandrov (2020). We find the $C I R^{Y}$ statistic convenient for two reasons. First, it combines in a single value the persistence and the size of the output response. Second, for small monetary shocks, like the ones typically considered in the literature, the area is completely encoded by frequency of price changes and the kurtosis of price changes.

\footnotetext{
${ }^{9}$ The proof can be established by using the symmetry properties of the even moments of the distribution. Noting that, for example, $N(\mu)=N(-\mu)$ and taking the derivative with respect to $\mu$ gives $2 N^{\prime}(0)=0$. See proposition 5 in Alvarez and Lippi (2019) for a rigorous proof.
} 
Formally, let the cumulative impulse response $\left(C I R^{Y}\right)$ of output for a monetary shock $\delta$ be:

$$
C I R^{Y}(\delta)=\int_{0}^{\infty} Y(t ; \delta) d t
$$

where $Y(t ; \delta)$ is the aggregate output $t$ periods after the shock $\delta$, measured in deviation from the steady state output. Using $f(x, t)$ to denote the cross-sectional distribution of gaps at time $t$, and considering an aggregate nominal shock $\delta$ which uniformly displaces the invariant distribution of the desired adjustments at time zero, so that $f(x, 0)=f(x+\delta)$ the output at time $t$ (in deviation from steady state) is given by

$$
Y(t ; \delta)=\frac{1}{\epsilon}(\delta-P(t))=\frac{1}{\epsilon} \int_{-\bar{X}}^{\bar{X}} f(x, t) x d x
$$

where $P(t)$ stands for the response of the aggregate price level at time $t$ and $1 / \epsilon$ is the industry's Marshallian wage elasticity, so that output is proportional to real wages (or real money balances). The second equality formulates the same relation in terms of the distribution of price gaps $x$. Our approach to characterize equation (3) is to compute the cumulated output measure for each firm, as indexed by its price gap $x$, and then aggregate over firms using the displaced time zero distribution $f(x+\delta)$, see Appendix A for details. ${ }^{10}$

We highlight a homogeneity property of the cumulated output response $C I R^{Y}$. Let Std $\equiv$ $\sqrt{\operatorname{Var}}$ be the cross-sectoral standard deviation of price changes in the economy with zero inflation. Also, with slight abuse of notation, let us write $C I R^{Y}(\delta ; N, S t d, K u r t)$ to emphasize the dependence of the $C I R^{Y}$ on some key steady-state moments. We have:

$$
C I R^{Y}(\delta ; N, S t d, \text { Kurt })=\frac{S t d}{N} C I R^{Y}\left(\frac{\delta}{S t d} ; 1,1, \text { Kurt }\right)
$$

The equation states that $C I R^{Y}$ is homogenous of degree -1 with respect to the frequency of price

\footnotetext{
${ }^{10}$ We stress that in computing such a measure we keep the decision rule constant at their steady state level. In Proposition 7 of Alvarez and Lippi (2014) we showed that, given the general equilibrium set-up in Golosov and Lucas (2007) and the lack of the strategic complementarities, such an approximation gives an accurate first order approximation. We also use the fact that after the first price change the expected contribution to output of each firm is zero since positive and negative output contributions are equally likely. This result, which holds around zero inflation, is convenient since it allows us to characterize the propagation of the monetary shocks without having to keep track of the time evolution for the whole distribution of price gaps.
} 
changes. This is intuitive as changing $N$ amounts to a rescaling of the time units, so that a doubling of $N$ is equivalent to everything happening twice as fast. The equation also shows that the standard deviation of price changes scales both the size of the $C I R^{Y}$ as well as the shock size. In particular this implies that for small shocks $\delta$, where a small shock must be interpreted as small relative to $S t d$, the only moments that matter for the $C I R^{Y}$ are the frequency and the kurtosis of price changes, since a first order expansion gives

$$
\operatorname{CIR}^{Y}(\delta ; N, S t d, \text { Kurt }) \approx \delta \frac{1}{N} \frac{\partial}{\partial \delta} C I R^{Y}(0 ; 1,1, \text { Kurt })
$$

Interestingly, for small values of $\delta /$ std, the first order expansion of $C I R^{Y}$ does not depend on the standard deviation of price changes.

Next we state the sufficient-statistic result of Alvarez, Lippi, and Oskolkov (2021): the cumulated output response following a small nominal shock $\delta$ is (see Appendix A for the proof):

$$
C I R^{Y}(\delta ; N, S t d, \text { Kurt })=\frac{\delta}{6 \epsilon} \frac{K u r}{N}+o\left(\delta^{2}\right)
$$

The result states that, with low inflation, the cumulated output response to a small shock is accurately approximated by the ratio of the kurtosis to the frequency of price changes, scaled by some constants. The approximation is accurate up to second order terms, so that the remainder is of order $\delta^{3}{ }^{11}$

The result in equation (6) is striking. It holds in a large class of inherently different models, from time dependent models a la Calvo, to canonical menu-cost models a la Golosov-Lucas, intermediate cases such as the Calvo-Plus by Nakamura and Steinsson or inherently random-menu cost models such as those of Caballero and Engel. Moreover, we have shown in Alvarez, Le Bihan, and Lippi (2016) that equation (6) holds in multi product models, and we have shown in Alvarez, Lippi, and Paciello (2016) that the same equation holds in a large class of costly information models that give rise to time-dependent rules, spanning classic models such as Taylor (1980); Caballero (1989); Reis (2006). The broad applicability of the same equation across such a different set of

\footnotetext{
${ }^{11}$ This happens since $C I R^{\prime \prime}(0)$ is zero, which follows from twice differentiating the $C I R$ and noting its antisymmetric nature, or $C I R(\delta)=-C I R(-\delta)$.
} 
models is the hallmark of the "sufficient statistic" result, a theoretical notion coined by Koopmans (1953); Marschak (1953), and recently revived by Chetty (2009); Badel and Huggett (2017) in public finance models. The central idea is to derive formulas to describe the effect of a policy that are functions of a few high-level elasticities rather than all the deep primitives of the models. In our case, this means that a two steady state moments fully capture the CIR across a wide range of models that differ in terms of the number of primitives and even in their fundamental micro structure.

Strategic Complementarities. The coefficient $\frac{\delta}{6 \epsilon}$ that multiplies the ratio of kurtosis over frequency in equation (6) is the one produced by a standard model, such as Golosov and Lucas (2007); Calvo (1983), or Nakamura and Steinsson (2010) with no (first-order) strategic complementarities. We briefly mention that in a model with strategic complementarities the coefficient would need to be scaled by a multiplicative term $\mathcal{S}$, as in $\mathcal{S} \frac{\delta}{6 \epsilon}$, as shown in Alvarez, Lippi, and Souganidis (2021). In what follows, we stick for simplicity to a model with no complementarities where $\mathcal{S}=1$, and further comment on the effects of complementarities when discussing our estimates below.

Key Assumptions and Limitations of the Sufficient Statistic Result. Three assumptions are key for the proof of equation (6). The first one is that the model has no inflation, so that several model objects display symmetry properties. While the assumption of zero inflation might seem restrictive, we argue that it provides a good approximation to models where inflation is low. The reason is that, as was noted above, that the $C I R^{Y}$ function has a zero cross partial derivative, $\left.\frac{\partial^{2}}{\partial \delta \partial \mu} C I R^{Y}\right|_{\delta=0, \mu=0}=0$, which implies that $\left.\frac{\partial}{\partial \delta} C I R^{Y}\right|_{\delta=0, \mu=0}=0$ is insensitive to small changes in the value of steady state inflation.

The second key assumption for the result to hold is that upon adjustment the firm completely closes the price gap, i.e. that $x$ is reset to zero. This assumption is violated in models with high inflation, or in models with price plans (as in Eichenbaum, Jaimovich, and Rebelo (2011)). In such cases equation (6) is not a good summary of the impulse response and other methods can be used to approximate $C I R^{Y}$. See Alvarez and Lippi (2019) and Alexandrov (2020) for some results on, respectively, price plans and high inflation. 
A third assumption is that $x$ follows a Brownian motion. This assumption allows us to exploit the identity $N \cdot \operatorname{Var}=\sigma^{2}$, and to use the Kolmogorov forward equation in the proof. In a model with leptokurtic shocks, such as Midrigan (2011), such equation fails to hold and kurtosis and frequency are not enough to summarize the $C I R^{Y}$. However, we note that for moderate deviations from the normal benchmark, which are consistent with the data on the distribution of firms' nominal shocks, the formula continues to provide a useful benchmark (see Section 5 in Alvarez, Le Bihan, and Lippi (2016) and the numerical results in Gautier and Le Bihan (2020)).

\subsection{An Empirical Test for the Sufficient Statistic Result}

This section uses the predictions developed above to derive an empirical test of the theory. We will consider an economy made of several sectors, indexed by $j$, assuming that firms within a sector are similar, i.e. that they have the same response to a common monetary shock. The thought experiment is to hit this economy with an aggregate monetary shock, and to use the variation in the responses observed across the sectors to test the theory.

For convenience of exposition, the above section and our main equation (6) focussed on an economy with a single sector. A similar result, however, turns out to hold at the sectoral level in a multi-sector version of the model. ${ }^{12}$ The multi-sector set-up allows sectors to differ in the variability of the idiosyncratic shocks $\left(\sigma_{j}\right)$, as well as in the pricing friction (each sector being associated with a function $\left.G_{j}(\psi)\right)$. In that multi-sector set-up, the theory predicts that $C I R^{Y_{j}}$, the cumulated output response of sector $j$, is related to the observed ratio $\frac{\text { Kurt }_{j}}{\text { Freq }_{j}}$ according to:

$$
C I R_{T}^{Y_{j}} \approx \frac{\delta}{6 \epsilon_{j}} \frac{\text { Kurt }_{j}}{\text { Freq }_{j}}
$$

where again the approximation is due to the fact that the theory is based on a second order approximation and that our measurement will use a finite horizon $(T<\infty)$.

Equation (7) suggests testing the theory using a linear empirical relation between the product-

\footnotetext{
${ }^{12}$ That setup assumes that households consume goods from several sectors $j=1, \ldots, J$, each entering the utility function in an additively linear way with a constant intertemporal elasticity of substitution $1 / \epsilon_{j}$ and linear leisure. Within each sector, a continuum of producers supply goods subject to the problem described above. Details are available upon request.
} 
level CIR of output over a long horizon, and the observed product-level ratios of kurtosis to the frequency of price changes. ${ }^{13}$ However, highly disaggregated sectoral output or real consumption series (at a monthly frequency) that match exactly the level of disaggregation and high frequency of observations typical of price data, are usually not available. In particular, in the case of France, there are no available monthly consumption volume data available at the same level of disaggregation as the CPI (we conjecture the same holds for other countries). We thus rely in the following on the cumulated impulse response of prices rather than output. One advantage of this strategy is also that both the micro and sectoral sets of variables derive from the same source of micro prices, ensuring consistency.

To obtain this alternative test, let us derive the relation between the cumulated response of output in sector $j$ at horizon $T, C I R_{T}^{Y_{j}}$, and the one of the price level at the horizon $T$, $C I R_{T}^{P_{j}} \equiv \int_{0}^{T} P^{j}(t) d t$, following a monetary shock of size $\delta$. Using the definition in equation (3) and equation (4) we have

$$
C I R_{T}^{Y_{j}} \equiv \int_{0}^{T} Y_{j}(t) d t=\frac{1}{\epsilon_{j}} \int_{0}^{T}\left(\delta-P^{j}(t)\right) d t=\frac{1}{\epsilon_{j}}\left(\delta T-C I R_{T}^{P_{j}}\right)
$$

where $\frac{\delta}{\epsilon_{j}} T$ is the cumulated change in nominal output following a permanent increase in money. ${ }^{14}$ Replacing $C I R_{T}^{Y_{j}}$ by its value in equation (7) we have the following prediction relating the cumulated response of prices and the ratio of the price change distribution for a large $T$ :

$$
C I R_{T}^{P_{j}} \approx \delta T-\frac{\delta}{6} \frac{\text { Kurt }_{j}}{\text { Freq }_{j}}
$$

From this equation, we derive an empirical linear specification linking the product-level CIRs of prices to a monetary shock and the observed product-level ratios of kurtosis over frequency of price changes (in levels). One advantage of this specification (using CIR of prices instead CIR of output) is that the predictions for prices are independent of the sectoral elasticity $\epsilon_{j}$, which simplifies how the regression coefficient should be interpreted. This provides an additional motivation for focusing

\footnotetext{
${ }^{13}$ Besides, this equation allows to compute the CIR of the aggregate economy output, and to assess the impact of heterogeneity in sectoral moments on the aggregate CIR - see Appendix A

${ }^{14}$ Note that when $T$ tends to infinity, as the CIR of output is finite, the CIR of prices diverges. This is an expected property as the price level is permanently higher (or lower).
} 
on the response of prices rather than output. We will thus estimate, as a baseline, the following linear regression:

$$
C I R_{T}^{P_{j}}=\alpha+\beta\left(\frac{\text { Kurt }_{j}}{\text { Freq }_{j}}\right)+\nu_{j}
$$

where $\alpha=\delta T$ and $\beta=-\delta / 6$ are the theory-implied values of the regression coefficients and $\nu_{j}$ is the regression's error term. In our empirical exercises, we have normalized our measure of the monetary policy shock so that $\delta=-1 \%$, leading, under a strict interpretation of the model, to the prediction that $\beta=1 / 6$ and that $\alpha=-T$ where $T$ is the time horizon (in months). In our empirical tests, $T$ will be set to either 24 months or 36 months. We refer to this regression as the baseline regression, or as a "constrained regression", since the specification imposes that kurtosis and frequency enter the regression as a ratio. ${ }^{15}$

We can further decompose equation (9) to investigate the restriction imposed by the theory on how kurtosis and frequency relate to the CIR. For that, we rely on a first-order Taylor expansion around the sample means $\bar{F}, \bar{K}$, and we get:

$$
C I R_{T}^{P_{j}} \approx C I R^{\bar{P}_{T}}-\frac{\delta}{6} \frac{\bar{K}}{\bar{F}} \frac{\text { Kurt }_{j}}{\bar{K}}+\frac{\delta}{6} \frac{\bar{K}}{\bar{F}} \frac{\text { Freq }_{j}}{\bar{F}}
$$

From this expression we derive an unconstrained version of the empirical test where we relate the CIR of prices to the ratio of the product-level kurtosis over its average, and the ratio of the product-level frequency over its average:

$$
C I R_{T}^{P_{j}}=\gamma+\beta_{k}\left(\frac{\text { Kurt }_{j}}{\bar{K}}\right)+\beta_{f}\left(\frac{F r e q_{j}}{\bar{F}}\right)+\nu_{j}
$$

The theory suggests that $\beta_{k}$ and $\beta_{f}$ (i.e. the slope coefficients of the regressors $\frac{K u r t_{j}}{\bar{K}}$ and $\frac{F r e q_{j}}{\bar{F}}$ ) are expected to have opposite sign and be equal in absolute value.

We emphasize that the theory gives no prediction on the extent to which kurtosis and frequency contribute to the "explained share of variance", or to the fit, of the regression. This contribution

\footnotetext{
${ }^{15}$ An interesting property of the specification in equation (10) is that, for some type of measurement errors namely a fraction of price change being spurious changes, of a small size - , the induced multiplicative bias on measured kurtosis and frequency is identical, so these biases do cancel. In other terms the specification is correct even though both kurtosis and frequency are measured with errors. See Appendix F for details.
} 
could be arbitrarily low or large, depending on the cross-sectoral dispersion of kurtosis and frequency, without invalidating the theory.

\section{Measuring Monetary Shocks and Sectoral Moments}

This section discusses the data used in the analysis, and the construction of the empirical statistics needed to test the sufficient statistic result. We will use variations across products to test the theory. We rely on the fact that there is cross product variability in the price adjustment statistics, and that equation (10) is expected to hold across different sectors. ${ }^{16}$ We need to estimate two types of statistics: (i) the cumulative impulse response of prices $\left(C I R^{P}\right)$ computed at the sectoral level, and (ii) the moments of the distribution of price changes for the corresponding products. Section 3.1 and Section 3.2, respectively, present our approach and results in computing those statistics.

Before providing more details on the construction of the objects underlying our test, we stress two important features of our empirical approach. First, we make use of a cross section of moments computed from two micro data sets of prices in France: a first one covering consumer prices and the other one producer prices. Both data sets are relevant for our purpose, and each has distinctive advantages. Consumer prices are observed directly and somewhat less prone to measurement issues (since they can be directly observed in outlets), offer a broader coverage of the economy (goods and services vs. only goods for PPI products) and consumer inflation is used for the definition of the monetary policy target. Producer price data are conceptually closer to the firms' pricing problem studied in standard macro models, and are not affected by sales and temporary promotions.

The second feature is that we identify the monetary shocks by imposing that they have the properties highlighted by the theory (in the spirit of the "sign restriction" approach). In particular, we want a (contractionary) shock to decrease output in the short run, to have a permanent negative effect on the price level, and to have no long-run effect on output. These characteristics are consistent with the theoretical model described above, and are thus desirable to perform a test of

\footnotetext{
${ }^{16}$ In the paper we use indifferently the terms "sectors" and "products". For PPI, product and sector classifications fully overlap, whereas for CPI, we will use product specific price indices.
} 
the sufficient statistics result. Note that in principle any common shock to the marginal cost of firms could be used to test the theory. Oil price shocks would for instance qualify, but empirically the sectoral dynamics following such a shock is strongly heterogenous making it hardly useable for a test in a finite sample. On the contrary, an aggregate monetary shock has the desirable features that it will eventually move all nominal prices by the same amount, leaving relative prices unaltered. We exploit this homogeneity property in our long-run identification of the monetary shock. Finally, we stress that another feature of our approach is that the construction of the $C I R^{P}$ variables does not use the micro data nor the sectoral moments, so there is no reason to expect any bias in favor (or against) the sufficient statistics result.

\subsection{Measuring the Sectoral Response to a Monetary Shock}

To estimate the $C I R^{P}$ for a large number of sectors of the French economy we employ a Factor Augmented VAR (FAVAR). The method was developed by Bernanke, Boivin, and Eliasz (2005)

and Boivin, Giannoni, and Mihov (2009). We closely follow the approach of Boivin, Giannoni, and Mihov (2009) as they focus on the response of sectoral inflation rates to monetary policy shocks. A brief description is as follows: ${ }^{17}$ the FAVAR is a model in which the dynamics of a large number of time series is governed by the evolution of a small number of times series, the factors, that are typically - but not necessarily - unobserved and follow a VAR process.

Formally the vector of a large number $n$ of time series $X_{t}$, called informational time series, are related to the factors $F_{t}$ by the following equation:

$$
X_{t}=\Lambda F_{t}+e_{t}
$$

where $F_{t}$ is a vector of dimensions $\mathrm{K}+\mathrm{M}$ of respectively unobserved and observed factors, and $e_{t}$ is a vector $n \times 1$ of error terms with zero mean. Following Boivin, Giannoni, and Mihov (2009) we allow one factor, the interest rate $i_{t}$, to be observed, so $F_{t} \equiv\left[\tilde{F}_{t} i_{t}\right]^{\prime}$ where the unobservable factors $\tilde{F}_{t}$ are to be estimated. Notice that the observable factors and the informative time series are two distinct objects that do not have any time series in common. The factors follow a VAR

\footnotetext{
${ }^{17}$ Appendix B describes the FAVAR model and discusses its framework.
} 
process:

$$
F_{t}=\Phi(L) F_{t-1}+v_{t}
$$

where $\Phi(L)$ is a lag polynomial of finite order and $v_{t}$ is an error term with zero mean and covariance matrix $Q$.

The unobserved factors can be estimated, typically by using a principal component analysis on a large number of "informative" time series. After this step is performed, it is possible to estimate a VAR in the estimated factors (along with the observed ones, if any). Once the VAR is estimated, it is possible to retrieve the impulse response function (IRF) of any informative time series to a monetary policy shock. This last point is crucial for our purpose to estimate the cumulative impulse response of prices for all sectors.

Of primary interest for our purpose is the response of sectoral prices to an aggregate shock. The dynamics of inflation in sector $j$ will, in our FAVAR set-up, governed by:

$$
\pi_{j t}=\lambda_{j} F_{t}+e_{j t}
$$

where $\lambda_{j}$ is a vector of loadings, recovered as the relevant row of matrix $\Lambda$. Equation (15) makes it clear that one can easily recover the IRF of sectoral inflation (and hence, prices) to a monetary shock from the IRF of the factors $F_{t}$ to the shocks.

We include three types of "informative time series" in vector $X_{t}$ : (i) macroeconomic data for France including aggregate industrial production, aggregate producer price index (PPI), the aggregate harmonized index of consumer prices (HICP), unemployment rate, (ii) financial and monetary variables relevant for the euro area including the monetary aggregate M3 in the euro area, the value of banknotes in circulation in the euro area, the euro exchange rate with respect to US dollar, yen, UK pound sterling, Swiss franc, Chinese Yuan Renminbi (iii) highly disaggregated series of industrial production, producer prices (PPI) and consumer prices (CPI), as well as some available disaggregated series for monthly consumption (16 broad categories of consumptions at an intermediate aggregation level, including, for instance, durables consumption, manufacturing goods consumption). As regards product-specific monthly price series, CPI price indices are available at 
the 5-digit level of the ECOICOP classification (e.g. '01.1.1.1' 'Rice') whereas PPI price indices in the manufacturing sector are available at the 4-digit level of the NACE rev2 classification of sectors (e.g. '08.11' 'Quarrying of ornamental and building stone, limestone, gypsum, chalk and slate'). Overall, we use 223 product-specific consumer price indices covering both goods and services and 118 producer price indices covering the manufacturing sector. In addition, our analysis uses the 3-month Euribor as a measure of the monetary policy variable. This variable will be treated as an observable factor, and we filter it following motivations and a procedure that are detailed below. All the data are monthly and the sample period is Jan. 2005 to Dec. 2019. We are interested in estimating the response of the disaggregated time series of prices (PPI and CPI) after a monetary shock; in our analysis an exogenous shock to the 3-month Euribor. In a first step, factors are computed from a Principal Component Analysis using the informative time series (in log difference). We extract the five principal factors (those with the largest contributions to the overall variance). We subsequently estimate a VAR with 12 lags for the 5 factors and the interest rate.

Identifying Monetary Policy Shocks and the Price Responses. To identify a contractionary monetary shock, and estimate the associated IRFs, based on our FAVAR results, we use a Cholesky decomposition of the variance-covariance matrix of the VAR innovations. Following a standard timing restriction, the Euribor is ordered as a last variable in the VAR. Notice that, imposing a Cholesky decomposition in this setup does not imply that the IRFs of informative time series cannot respond simultaneously to the monetary shock. The $C I R^{P}$ is computed cumulating the responses of sectoral price levels over a large number of periods (see next section for a discussion).

For robustness purposes we consider several approaches in identifying monetary policy shocks. In our baseline approach we impose a "long run neutrality" restriction. Specifically, we impose (i) that output comes back to its original level in the long run after a monetary shock and (ii) that all sectoral prices have identical responses -equal to that of the aggregate price index- in the long run. ${ }^{18}$ Both of these restrictions are consistent with the money neutrality hypothesis. To

\footnotetext{
${ }^{18}$ In practice, we impose this restrictions at the horizon of 8 years. Note this horizon is independent and sub-
} 
implement the latter restriction in the baseline FAVAR specification, we proceed following Boivin, Giannoni, and Mihov (2009).

We also consider an alternative case when no long-run restriction is imposed and relative prices are unconstrained in the long run (a case considered by Boivin, Giannoni, and Mihov (2009) along with the one with long-run restrictions). In addition, we explore a third alternative identification procedure, following Gertler and Karadi (2015), and use a High Frequency Identification in the VAR set-up. This allows us to handle simultaneity concern without resorting to a timing assumption as in the Cholesky approach. For the HFI approach, we use the data for monetary surprises in the euro area from Altavilla et al. (2019), who rely on market interest rate changes around the times of ECB Governing Council meetings. ${ }^{19}$

In all FAVAR specifications, we normalize the shock, so that the monetary policy shock produces a $1 \%$ long-run decrease in the aggregate price level. This normalization assumption (which has no bearings in terms of inference) departs from the usual approach to normalizations imposing that the shock produce a, say, 25 basis points effect on impact on the nominal interest rate. The normalization allows an easier comparison with our theoretical model (where the size of the shock is proportional to the long run response of the price level) and facilitates the interpretation of results relating the $C I R^{P}$ to the sufficient statistic.

Filtering the Euribor. Reflecting in particular the marked downward trend in the nominal interest rate over the sample period (itself partly related to the decline in the natural rate of interest, see Figure A) the VAR estimates based on unfiltered interest rate data produce impulse response functions that are not consistent with the response of output and inflation to a monetary policy shock suggested by the model. The theory suggests that a (contractionary) monetary policy shock triggers a transient, and negative, impact on inflation and output. ${ }^{20}$ Our approach is to use an HP filter with parameter $\lambda^{H P}$ delivering the expected properties. As is documented in stantially longer than the one over which we will compute cumulated IRFs (2 and 3 years).

${ }^{19}$ In further robustness analysis, we also report results using the 2-year German Bond rate as the policy rate and using the same HFI approach, to account for non-conventional monetary policy shocks.

${ }^{20}$ Identifying well-behaved monetary policy shocks for the euro area is particularly challenging over the sample period, in particular due to the proximity of the effective lower bound on interest rates - see Andrade and Ferroni (2021) and Jarocinski and Karadi (2020) for investigations in the context of information shocks. 
Appendix C, we select a value of $\lambda^{H P}=1000$, a smaller value than the one traditionally used with monthly data. Using this parameter value, we are able to recover IRFs that (both for CPI and PPI) feature a negative response of prices and output for the aggregate price index, as well as the largest number of sectors for which the individual price response is negative after 24 or 36 months. We stress that our procedure for selecting the filter parameter makes no use of the microeconomic data or the sectoral moments, so it is not biasing towards finding some relevance of the sufficient statistics results. Our FAVAR estimation procedure is designed to produce a shock that has a common effect on all sectors and can be interpreted as a monetary policy shock.

VAR Results: IRFs and $C I R^{P}$ 's. Our estimated FAVAR provides theory-consistent results for the responses of aggregate variables to a monetary shock. As presented in Appendix Figure D, after a contractionary policy shock the interest rate increases and subsequently decreases, going back to its steady state level after two years. Industrial production immediately reduces after a contractionary monetary policy shock, then gradually recovers. The production price index declines following the shock, then recovers towards the new steady-state value. The aggregate consumption price index reacts similarly.

We focus our analysis on the objects used to test the sufficient statistic result, namely the responses of sectoral producer and consumer prices, as derived from the FAVAR. Figure 1 reports the estimated IRFs of production and consumer price series. In each panel, the blue line (Aggr PPI/HICP) represents the IRF of the aggregate PPI/HICP series. Dashed red lines are the IRFs of different sectors partially aggregated, at the 2-digit level for PPI, and 1-digit level for CPI. ${ }^{21}$ The thick red line is the average of all the dashed red lines. In both panels, red and blue curves have a very similar shape, an expected property, as the average of sectoral responses should closely approach the response of the aggregate price index. ${ }^{22}$ In both figures, we impose that the long run price response is -1 percent at a long horizon ( 8 years). The transitory dynamics is however heterogeneous across sectors. Most of them display a through in prices after 1 to 2 years after the

\footnotetext{
${ }^{21}$ Our PPI/CPI series are available at the 4-digit and 5-digit levels, and the dashed red lines are constructed as the arithmetic average of estimated IRFs.

${ }^{22}$ The small discrepancy between these two curves is due to the fact that the aggregate price index is a weighted price index whereas the average of sectoral IRF is unweighted.
} 
shock. $^{23}$

Finally, using the estimated IRFs of the PPI and CPI, we construct the $C I R^{P} \mathrm{~s}$ for each sector/product category, as the sum of the respective IRF from time zero up to a time horizon $T$. The sectoral $C I R^{P}$ s are the most important object of interest in this section, since the sufficient statistic result relates these measures to the cross sectional moments of the price change distribution. We consider two different values for $T$, respectively 24 and 36 months (see Table A in Appendix for descriptive statistics on product-specific $\left.C I R^{P} \mathrm{~s}\right)$.

\subsection{Measuring Micro Moments}

Consumer Price (CPI) Micro Data For consumer price micro data, we rely on longitudinal data sets of monthly price quotes collected by the Institut National de la Statistique et des Études Économiques (INSEE) to compute the monthly French CPI (Consumer Price Index). Stacking data sets used in Baudry et al. (2007), Berardi, Gautier, and Le Bihan (2015) and Berardi and Gautier (2016) and extending the data set to September 2019, we obtain a long sample covering a period of about 25 years between August 1994 and September 2019.

The data set contains about 30 million of price quotes, and covers about $60 \%$ of the CPI weights. $^{24}$ Price changes are computed as log-differences of prices, and we exclude price changes due to sales. To compute price adjustment moments, we have first dropped data collected around VAT changes (i.e. in Aug.-Sept. 1995, Sept.-Oct. 1999, April-May 2000, July-Sept. 2009, Jan.Feb. 2012 and Jan.-Feb. 2014) and before and after the euro cash changeover (between Aug. 2001 and June 2002). We have also dropped price changes smaller than $0.1 \%$ in absolute values, in both data sets, in order to control for possible small price changes due to measurement errors (Eichenbaum et al. (2014)).

We compute price adjustment statistics excluding sales, as the model is not able to reproduce price changes due to sales. For identifying sales we rely on an INSEE flag variable that identifies

\footnotetext{
${ }^{23}$ In Appendix D, we report similar results for all the different specifications of the FAVAR model we have estimated.

${ }^{24}$ Some categories of goods and services are not available in our sample: centrally collected prices, among which car prices and administered prices (e.g. tobacco) or public utility prices (e.g. electricity), as well as other types of products such as fresh food or rents.
} 
whether a price corresponds to a sale price, either in the form of seasonal sales or temporary promotional discounts. Sales are mostly concentrated in some sectors (i.e. clothing and shoes, and furnishings).

We identify products at the 5-digit level of the ECOICOP product classification, which is the most disaggregated level for which sectoral price indices are available. For each product, we compute the frequency of price changes as the ratio between the number of price changes (but excluding price changes due to sales) and the total number of prices for this product. We also compute the kurtosis of price changes, as well as other moments of the price change distribution (such as average price changes, the standard deviation of price changes and the skewness of price change distribution), at the product level. Overall, for CPI products, our baseline data set contains price adjustment moments for 223 different "ECOICOP-5" products.

Measurement of kurtosis is notoriously a challenging issue, as large values of price changes, and outliers, can have an important impact on kurtosis. Very large kurtosis values tend to be obtained when not correcting for measurement errors. ${ }^{25}$ In our baseline, we drop from the calculations price changes larger than $25 \%$ in absolute values, which corresponds to about five percent of all price changes. As robustness, we provide results with alternative values for the thresholds used to defining for outliers and address measurement errors concern (for very large or very small price changes in absolute values). Drawing on Alvarez, Lippi, and Oskolkov (2021), we also provide results using a measure of kurtosis including a correction for unobserved heterogeneity (see Appendix E for details). Alternative kurtosis measures are highly correlated across products.

Producer price (PPI) Micro Data. We rely on micro price data collected by INSEE to construct the French Producer Price Index (the same data set as the one used in Gautier (2008)). Reported prices must be observed at the "factory gate", excluding transport and commercialization costs, or invoiced VAT. Our sample contains more than 1.5 million price reports between January 1994 and June 2005. Overall, more than $90 \%$ of the price quotes used to compute the French PPI are available. The PPI covers all products manufactured and sold in France by industrial firms,

\footnotetext{
${ }^{25}$ Note however that excluding sales by itself does not decrease the degree of kurtosis, see for instance Gautier and Le Bihan (2020).
} 
which includes sections C (Mining and quarrying), D (Manufacturing) and E (Electricity, gas and water supply) of NACE Rev 2 classification. ${ }^{26}$ The data set has been investigated in Gautier (2008) where further details are available. Contrary to CPI prices, there is no flag for temporary promotions or sales. We assume, consistent with Nakamura and Steinsson (2008), that there are no sales in producer prices. Like for CPI, price changes are computed as log-differences of prices.

For each NACE 4-digit sector, we compute both the frequency of price changes and the kurtosis of non-zero price changes, as well as other moments of the price change distribution. Unlike with CPI, large price changes are much less frequent (reflecting, and confirming, that sales or temporary promotions are not a usual practice in the mainly business-to-business context of producer prices) and only $2 \%$ of all price changes are larger than $22 \%$ in absolute value. To measure kurtosis, we drop price changes larger than $15 \%$ in absolute values (which correspond to less than $5 \%$ of all price changes) and we test the robustness of our results to this definition of price change outliers. We restrict to the subsample of sectors for which an aggregate sectoral price index is available from the statistical office, so as to match micro moments with time-series macro evidence in our subsequent analysis. This result in a baseline sample containing 118 sectors.

Basic statistics for the micro data underlying both the CPI and the PPI, are presented in Table 1 and Figure 2a and Figure 2b. Consumer prices are more rigid than producer prices, with average frequencies of price changes of 10.6 percent and 19 percent respectively. The distribution of price changes has fat-tails for both data sets, with a virtually identical value of the average unweighted kurtosis of 5.0 in both data sets. One main important takeaway is there is some cross-sectoral dispersion in frequency and kurtosis of price changes, for both consumer prices and producer prices - as apparent from the interquartile ranges or standard deviations, and from the full distribution of moments plotted on Figure 2a and Figure 2b. The frequency of price changes however seems to show relatively more cross-sectoral variability than the kurtosis of price changes. While alternative corrections for measurement error and unobserved heterogeneity do change the average value of kurtosis, they do not substantially affect the degree of cross-product heterogeneity however.

\footnotetext{
${ }^{26} \mathrm{NACE}$ is the general "classification of economic activities within the European Community". Some sectors are excluded from collection: mining of uranium and thorium, ores, publication, processing of nuclear fuel, weapons and ammunition, building and repairing of ships and boats, manufacturing of aircraft and spacecraft, and recycling.
} 
Cross-sectoral characteristics of both our CPI and PPI data sets are consistent with available international evidence. As regards consumer price data, Berardi, Gautier, and Le Bihan (2015) using the same data, provide a detailed comparison of CPI data moments in France with those in the United States, based on detailed moments reported by Nakamura and Steinsson (2008). They conclude that patterns are quite similar, whenever sales-related price changes are disregarded (as the pattern of sales is however much more prevalent in the United States). Regarding producer prices, Vermeulen et al. (2012) provide a comparison of the patterns of price setting in the United States and 6 euro-area countries, including France - relying for that particular country on the same data set as we use. They conclude patterns of producer price rigidities are very similar - albeit the size of price changes is typically larger in the United States than in Europe. The above-mentioned international evidence mainly focuses on the frequency of price changes, as well as on the first two moments of the distribution of price changes. Evidence is scarcer on kurtosis. For US PPI data, Hong et al. (2020) report and average kurtosis of 4.9. With consumer price data, Cavallo (2018) report a median kurtosis of 4.8 in a large sample of countries based on "scraped" data. These values, all obtained after correcting for measurement errors in the same spirit as we do, are thus much in line with our baseline values.

\section{Testing the Theory: Results}

This section presents the results of the empirical tests developed in Section 2.3 using as inputs the variations across products in the real effects of monetary policy, as measured in section Section 3.1, and in the microeconomic price adjustment moments, as measured in Section 3.2. Section 4.1 presents our baseline results while Section 4.2 presents broader tests that include "placebo" moments in the regression.

\subsection{Estimates of the Baseline Empirical Specification}

This section presents our baseline estimation results. A visual summary of these results is provided by Figure 3, that is the scatter plots of $C I R^{P}$ at horizon 36 months against the ratio Kurt/Freq, 
for the different FAVAR specifications and for both PPI products (top panel) and CPI products (bottom panel). For most of the specifications, we find a positive relationship in the cross section of products between the value of $C I R^{P}$ and the value of the ratio Kurt/Freq.

Table 2 reports results for equation (10), the baseline "constrained" regressions for an horizon $T$ equal to 24 or to 36 months. We consider separately the $C I R^{P}$ of producer prices (Panel A) and the $C I R^{P}$ of consumer prices (Panel B). In each panel we consider three specifications for the identification of the monetary policy shock: the baseline one, with Cholesky identification and long run restriction on relative prices; a first alternative with Cholesky identification and not imposing any restriction on the long-run effect on relative prices; and a second alternative where identification relies on High Frequency surprises and external instruments.

For producer prices (Panel A), the estimated slope coefficient associated with the Kurt/Freq ratio turns out to be positive and statistically significant in all cases, whereas the constant term is negative and statistically different from zero. These results are consistent with the theoretical framework. A positive sign for the coefficient associated with Kurt/Freq ratio is expected since a contractionary monetary policy shock has a negative effect on output, and the products with higher Kurt/Freq ratios are expected to experience, in absolute terms, larger output effects. Consistently, they will experience a less negative effect on prices, resulting in the cross-section regression in a positive coefficient associated with the Kurt/Freq ratio. A higher Kurt/Freq ratio can reflect either less frequent price adjustments, less price selection or both, implying larger (absolute) real effects of a monetary policy shock. The last columns of Table 2 report results without the long-run restriction, and those using the HFI approach. Coefficients are significant and with expected signs, as in the baseline. In the former case however, coefficients are larger than in the baseline, presumably reflecting the larger degree of variability of the $C I R^{P}$ 's in that case (see Table A in Appendix D). ${ }^{27}$

For consumer prices the results are mixed (Panel B of Table 2). In the baseline specification the Kurt/Freq ratio is not significant, but it is significant for the two alternative specifications

\footnotetext{
${ }^{27}$ The results relying on the FAVAR with long-run restrictions are more consistent with our theoretical set-up, while the FAVAR without these restrictions puts less constraint on the data but makes the size of the coefficients more difficult to relate to the exact predictions of the theory.
} 
(significance is at the $5 \%$ level for the 36 months horizon). ${ }^{28}$ Finally, in all specifications for both PPI and CPI, we find the intercept to be negative and statistically different from zero: on average, a contractionary monetary policy has a negative cumulated effect on prices at medium and long-run horizons (consistent with predictions of equation (9)). ${ }^{29}$

To further investigate the relevance of both the kurtosis and the frequency of price adjustments in explaining the propagation of monetary shocks, we report in Table 3 the estimate for equation (11), an "unconstrained" version of the regression that allows for a potentially different effect of frequency and kurtosis. ${ }^{30}$

For PPI products (Panel A), we find that the estimates are consistent with the theoretical predictions. First, a larger product-level frequency is associated with a relatively more negative effect on the $C I R^{P}$ for this product: if prices are more flexible, prices will decline faster. The real effects of monetary policy will also be smaller. Second, a higher kurtosis is associated to a smaller reaction of prices in that sector, resulting in a positive coefficient in the cross-section regression - since the $C I R^{P}$ is negative following a contractionary shock. This effect is significant: a higher kurtosis is associated with less selection effect leading to a lower $C I R^{P}$ of prices in absolute value and increasing the importance of the real effects of monetary policy. Moreover, it cannot be statistically rejected that slope coefficients associated with frequency and kurtosis are equal in absolute value, as predicted by the theory. ${ }^{31}$

For CPI products (Panel B of Table 3) we also find - in all cases - a negative and significant relationship across sectors between frequency and the $C I R^{P}$, and that the slope coefficient associated with kurtosis is positive. As for PPI products, we find that a positive relationship between kurtosis and $C I R^{P}$. At the same time, in the Cholesky case with no long-run restriction the estimate is however not significantly different from zero. Moreover, in the case with Cholesky

\footnotetext{
${ }^{28}$ In Table $\mathrm{C}$ of Appendix $\mathrm{G}$ we also provide results for the specification using a log ratio as the right-hand-side variable, and results are consistent: we find a positive and statistically significant effect for PPI, and more mixed for CPI products at both horizons.

${ }^{29}$ Note our identification assumptions for the FAVAR might contribute to this result, however, the restrictions are imposed on the long-run values of the IRF and not on the $C I R^{P}$ per se (i.e. how the IRF converges to its long run value).

${ }^{30}$ In Figure I, Figure J and Figure K in Appendix D we provide scatter plots of the $C I R^{P}$ and Kurt/Freq log ratios but also scatter plots of the $C I R^{P}$ and $\log$ of frequency and kurtosis for the different FAVAR specifications. They show a negative relationship between frequency and $C I R^{P}$ and positive between $C I R^{P}$ and kurtosis for all specifications (in particular PPI products) and these relations do not seem to be driven by any particular product.

${ }^{31}$ Table B in Appendix G reports p-values of formal Fisher tests from the estimated parameters.
} 
identification and long-run restrictions, we cannot reject that slope coefficients associated with frequency and kurtosis are equal, as predicted by the theory (Appendix Table B). Finally, in almost all specifications, we find the intercept $\gamma$ to be negative and statistically different from zero as predicted by theory (equation (11), recalling the considered monetary policy shock is negative).

Besides, the model provides not only predictions on the size of the coefficients of the regressions, but also on the amplitude of the coefficients for both constrained and unconstrained versions of the model. In the constrained version of the model, $\beta$ is predicted to be equal to $\frac{-\delta}{6}$ which is $1 / 6 \approx 0.167$ in our case since we have normalized the shock to $-1 \%$. Also, the intercept $\alpha$ should be equal to $\delta T$, hence in our cases to -24 or $-36 .^{32}$ In the unconstrained model, $\beta_{f}$ and $\beta_{k}$ are predicted to be both equal to $\frac{\delta \bar{K}}{6 \bar{F}}$ in absolute values, coefficients in absolute values should be equal to 4.4 for PPI and 7.9 for CPI. The constant of the model should be equal to $-\delta T+\frac{\bar{K}}{6 \bar{F}}$ which is equal to -20 for PPI and -16 for CPI at the horizon of 24 months and -16 for PPI and -28 for CPI at the horizon of 36 months. Note that testing these predictions is much more demanding for the empirical exercise and depends a lot on the degree of precision of our estimates. However, looking at the order of magnitudes of results in Table 2 for the specification relying on a Cholesky identification with long run restrictions, estimates are broadly in line with the predictions for PPI. It is less the case for CPI. Table B in Appendix G reports the results of more formal tests. For the unconstrained version of the model, we find that baseline results are fully in line with predictions on the amplitude of the coefficients for both PPI and CPI products and we cannot formally reject that the size of coefficients are consistent with model's predictions. As discussed in Section 2.2, after the sufficient statistic result was presented in equation (6), the predictions for the absolute value for the coefficients of the Kurt/Freq ratio are based on the assumption that the model features no strategic complementarities, or that $\mathcal{S}=1$. Allowing for the possibility of non-negligible strategic complementarities would provide us with one more parameter, $\mathcal{S}$, to be estimated: the regression in equation (10) would feature a coefficient given by $\mathcal{S} \beta$ that would allow to rationalize a wider range of estimates. We think that a better understanding of the quantitative importance of strategic complementarities, along the lines of the investigations by Klenow and

\footnotetext{
${ }^{32}$ Besides, the ratio $\alpha / \beta$ is predicted to be equal to $-6 T$, i.e. -144 at horizon 24 months and -216 at the horizon of 36 months.
} 
Willis (2016) and Beck and Lein (2020) is needed to address this point more thoroughly.

\section{2 "Placebo" Tests}

While the above results are consistent with the "sufficient statistic" property, a sufficient statistic property predicts something broader: it implies that the effect of a monetary shock should be related to the ratio "kurtosis over frequency" but it also implies that other moments of the price distribution should not matter in this relationship. To test this prediction, we run a regression in which we add to our baseline regressions three additional moments of the price change distribution computed at the product-level: the average size of (non-zero) price changes, the standard deviation and the skewness of price adjustments. This exercise can be considered as a "placebo" test of our baseline regressions, testing that our main result is not driven by correlations between frequency or kurtosis and other moments of the price change distribution.

Table 4 shows the results for this specification using moments in levels. For the PPI samples (Panel A) we find that the ratio of kurtosis over frequency has a significant positive effect at 5\% level across all specifications (except the case with Cholesky identification and a 24 month horizon, where significance is at 10\%) and the coefficients are highly similar to the ones obtained in Table 2, i.e. in the baseline case. Importantly, we also find that neither the average size of price changes, nor the standard deviation of prices changes, nor the skewness of price changes, do have statistically significant effects (one single exception being the skewness variable in the HFI identification for the 36-month horizon). These two results are fully consistent with the theoretical predictions.

We have estimated an unconstrained version of the "placebo" regression (see Table D in Appendix G). Results for PPI products are broadly robust, although the degree of significance decreases a bit, presumably owing to multi-colinearity. Coefficients associated with placebo moments are never significant at 5\% and only significant twice at 10\% (note that given we consider results for 6 specifications and 3 placebo moments, the fraction of significant coefficients is in line with what one would expect under the null of no effect).

In the case of CPI products (Panel B of Table 4), support for the theoretical predictions is -as 
with the baseline specification- somewhat more mixed. The coefficient on Kurt/Freq is positive and significant in only half of the cases. The coefficient associated with the "placebo" moments are in some cases significant (in 6 cases out of 18).

\section{Robustness Analysis}

This section explores the robustness of our findings with respect to several dimensions: i) we test whether our main results are driven by products with extreme values of $C I R^{P}$, as the distribution of $C I R^{P}$ values shows some very large positive and negative values - i.e. possible outliers; similarly, we present results removing products with extreme values of frequency of price changes, kurtosis or the ratio Kurt/Freq (Section 5.1); ii) we investigate whether our results are robust to kurtosis measurement issues related to product heterogeneity, or very large or very small values of price changes (Section 5.2); iii) for CPI products, we investigate the extent to which sales and promotions affect the results (Section 5.3); iv) we run regressions in which we include sectoral "fixed effects" to investigate which sources of sectoral variations are important to explain the relation between $C I R^{P}$ and Kurt/Freq ratio (across or within broad sectors) (Section 5.4); v) we report results using the 2-year German bond instead of the 3-month Euribor when identifying the model using a high-frequency identification with external instruments strategy (Section 5.5); vi) we consider the case excluding CPI from the FAVAR (hence from the full analysis) (Section 5.6); vii) finally, we report results for a subsample which excludes products with a large drift in prices (Section 5.7).

\subsection{Removing Extreme Values of $C I R^{P}$, Freq, Kurt or Kurt/Freq}

Our first robustness exercise consists of checking whether our main results are driven by some products for which the cumulative response of prices, frequency or kurtosis of price changes, is either extremely low or extremely high. For that we define 4 sub-samples, considering separately CPI and PPI products, in which we remove $5 \%$ of products corresponding to the $2.5 \%$ largest or the $2.5 \%$ smallest values for: (i) the $C I R^{P}$, (ii) ratio kurtosis over frequency, (iii) kurtosis of non-zero price changes or (iv) frequency of price changes. ${ }^{33}$ We run our baseline regression (as well

\footnotetext{
${ }^{33}$ For CPI, in each subsample, 10 different products are excluded whereas for PPI 6 different products are excluded.
} 
as unconstrained specifications) on each of these subsamples. Results of robustness regressions are all contained in tables in Appendix G (see Table E for the constrained specification with PPI products, Table F for CPI products, and Table G and Table $\mathrm{H}$ for results of unconstrained specifications).

For PPI products, removing products with extreme values of $C I R^{P}$ (Panel A of Table E), ratio Kurt/Freq (Panel B), kurtosis (Panel C), or frequency (Panel D), does not alter our baseline conclusions: the slope coefficient associated with the ratio Kurt/Freq is positive and significantly different from 0, and estimated coefficients are very close to the ones estimated in our baseline exercise. Similarly, in unconstrained regressions, results are in line with the ones using the full sample of products: all the results are consistent with the theoretical predictions including the equality of coefficients in absolute values for slope coefficients associated with frequency and kurtosis.

For CPI products, in the constrained model, results obtained when removing 'extreme' products are in line with baseline results: in most specifications, the ratio Kurt/Freq is positively related with $C I R^{P}$ but weakly statistically different from 0 . The strongest relationship is obtained when we exclude extreme values of kurtosis. For the unconstrained specification, in all cases, the coefficient associated with kurtosis is positive and significantly different from 0 (in most cases at $1 \%$ level) whereas the coefficient associated with frequency is negative and statistically significant in a majority of cases. However, the estimated parameter associated with frequency is found positive or non-significantly different from 0 in several cases for the model using Cholesky identification and a long-run restriction. Overall, for CPI products, results are more mixed and the negative relationship between frequency and $C I R^{P}$ is less clear.

\subsection{Issues with the Measurement of Kurtosis}

The measurement of kurtosis is known to be severely affected by unobserved heterogeneity. We run robustness regressions in which we use a measure of kurtosis, based on Alvarez, Lippi, and Oskolkov (2021), that takes into account product-level unobserved heterogeneity (Appendix E provides details on how we compute this robust measure of kurtosis). Results (reported in Table I of Appendix $\mathrm{G}$ ) are very much in line with the ones in our baseline regressions. For PPI, the coeffi- 
cient associated with the $K u r t / F r e q$ ratio is positive, and significant in all specifications, whereas for CPI this is the case in two of the three specifications. In the unconstrained regression, results are very consistent with theoretical predictions for both PPI and CPI products in the specification using a Cholesky decomposition identification and imposing the long run restriction. In the two other specifications, most results of unconstrained specifications are in line with theoretical predictions.

Another possible measurement issue is the high sensitivity of kurtosis to the definition of price change outliers, namely here to either very large, or very small price changes, in absolute values. In the baseline regressions, we have used kurtosis measures calculated on the sample of price changes smaller in absolute value than $15 \%$ for PPI price changes and than $25 \%$ for CPI price changes (i.e. 5 percent of all price changes in both cases) and we have excluded price changes below $0.1 \%$ in both cases. We here test the robustness of our results to modifying the thresholds defining extreme price changes. In a first exercise, we investigate the role of large price changes and we set the thresholds defining extreme values to $25 \%$ for PPI price changes and $35 \%$ for CPI price changes (which corresponds to excluding about $2 \%$ of all price changes). In a second exercise, we set the threshold for small price changes to $0.5 \%$ (which corresponds to about $5 \%$ of all price changes). ${ }^{34}$ The results overall remain in line with the baseline results (see Table K and Table J in Appendix G). Standard errors of coefficients associated with kurtosis are however much higher, lowering the significance of the estimated coefficients, in particular for large producer price changes.

Finally, kurtosis might not be the sole object raising measurement error issues in our set-up. For instance CIR is arguably as well subject to some measurement error. To investigate further the robustness of our findings to other sources of measurement errors, we perform the reverse regression with the $K u r t / F r e q$ ratio as a function of the $C I R^{P}$. Indeed the theory points to a relations between the two moments, but does not prescribe any "natural" way of selecting which should be the left-hand side variable, and which should be the right-hand side variable. Results of this regression are presented in Table L in the Appendix. As expected they provide a similar degree of support for the theory as our baseline, with typically positive and significant coefficients

\footnotetext{
${ }^{34}$ We have also run similar exercises with other definitions of small and large price changes and conclusions are very similar.
} 
on the CIR variable. However, the magnitude of coefficients is typically much lower than the one we can recover as the inverse of the corresponding parameters in the baseline regression. This is consistent with a possible bias in the measurement of CIR.

\subsection{Role of Sales for CPI Products}

For CPI products we further investigate robustness by excluding products for which price changes are mainly due to sales. The extent of sales could indeed affect price adjustment moments even if we have removed price changes observations due to sales in the calculation of these moments. In particular, if a very large majority of price adjustments are due to sales or promotions in one sector, the pricing moments excluding these changes might be not very representative of the typical price changes. We thus run robustness exercises removing all food, clothing/footwear and furnishings goods, as within these broad sectors, most products are largely affected by seasonal sales and replacements. ${ }^{35}$ In a second exercise, we exclude CPI products for which more than 10 percent of all price changes due to sales (the 10 percent fraction corresponds to the median value among all CPI products).

When removing the three broad sectors that are mostly affected by seasonal sales (Panels A and $\mathrm{B}$ of Table $\mathrm{M}$ in Appendix $\mathrm{G}$ ), we find a positive and significant effect of the ratio kurtosis over frequency in all specifications. In unconstrained specifications, we also find that estimated coefficients associated with both frequency and kurtosis have the predicted sign and are significant. In the specification using the Cholesky identification and imposing a long-run restriction, we also cannot reject that the equality of coefficients in absolute values for slope coefficients associated with frequency and kurtosis (as predicted by the theory).

When removing products for which the share of sales in price changes is larger than 10 percent, the coefficient associated with the Kurt/Freq ratio is larger than in the baseline case, but still not significant in the specification Cholesky imposing a long run restriction. In the unconstrained specification of the regression, frequency has a negative and significant effect, whereas kurtosis has a positive effect but only significant in the "HFI IV" specification. In this exercise, however, the

\footnotetext{
${ }^{35}$ These products correspond to COICOP 01.1, 03 and 05 in the product classifications.
} 
number of products, hence the sample size, is much more limited than in other regressions.

\subsection{Including Product-level "Fixed Effects"}

We run regressions in which higher-level sectoral "fixed-effects" are included, to investigate whether the relation between $C I R^{P}$ and the pricing-moments still holds within a more disaggregated level of sectoral breakdown. This exercise informs us on the sources of product variability that help identify the relation between $C I R^{P}$ and the cross sectional moments: broad sector differences versus within-sector variability. For that, we add sectoral fixed effects at the 2-digit level for both CPI and PPI products (there are 38 such "intermediate aggregation level" sectors for the CPI, and 24 in the case of the PPI). Results are reported in Table N in Appendix G. For PPI products, adding sectoral dummy variables weakens the significance of the estimated parameters, but the results are qualitatively and -for most of coefficients- quantitatively the same as in our baseline regressions. The results are again consistent with the theoretical predictions. Interestingly, for CPI, the Kurt/Freq ratio is now positive and significant in all specifications. In the specifications 'Cholesky with long run restriction' and 'HFI with long run restriction', both kurtosis and frequency have a significant effect with the expected sign. We note however that the addition of sectoral fixed effects significantly reduces the sources of cross-sectional variations, lowering the precision of the estimates.

\subsection{Two-year German Bond Rate}

In this robustness, we alter the policy rate used in the FAVAR estimation where the shock is identified using an external instrument approach. The main motivation is that over the last part of our sample the short-run policy rate was arguably constrained by the proximity of the effective lower bound for interested rates, and the ECB engaged in unconventional monetary policies intended to influence long term interest rates. ${ }^{36}$ We use the 2-year German sovereign bond rate, a relevant risk-free long term interest rate, instead of the 3-month Euribor rate. ${ }^{37}$ Results using this

\footnotetext{
${ }^{36}$ Note however that the policy rate was negative from 2014, and statements by the ECB indicate that the lower bound was not actually reached afterward.

${ }^{37}$ Jarocinski and Karadi (2020) use the 1 year and 2 year German bond as a policy variable in their analysis of ECB monetary policy.
} 
specification of the FAVAR model are reported in Appendix D. ${ }^{38}$

Results relating sectoral CIR from this FAVAR model and the sufficient statistic, for PPI products, are in line with the baseline (see Table $\mathrm{O}$ in Appendix G). The coefficient associated with the Kurt/Freq ratio is positive and significantly different from 0 (and we cannot even reject the coefficient being equal to the predicted value of $1 / 6 \approx 0.167$, and the intercept being equal to $-T$ for both horizons). In the unconstrained specification, the frequency and kurtosis have significant effect and we cannot reject the equality of the absolute values of these coefficients. For CPI products, only the frequency has a significant coefficient in the case with long-run restriction, whereas the ratio kurtosis over frequency has no significant effect. In the case without imposing the long run restriction, the ratio has the positive expected sign.

\subsection{A FAVAR with only PPI Sectoral Data}

In this exercise, we carry out the analysis removing the CPI sectoral data from the FAVAR and thus producing cross-sectoral regressions only for PPI. The motivations for carrying such an exercise are mainly twofold, and related to concerns with the CPI data. Note that, even if one restricts interest to the cross sectoral-regressions related to PPI data only, in our baseline set-up these are potentially affected by the properties of CPI data, since CPI data will influence the computation of the factors and hence of sectoral IRFs for PPI as well. A first concern is that the IRF of CPI prices to a contractionary shock is - as apparent from the IRFs reported in the Appendix - positive in a significant number of cases, which is not directly consistent with our baseline theoretical set-up. Second, considering PPI only allows us to circumvent to a large extent the issues resulting from seasonality in the data, which mainly stem from CPI products (through the timing of sales). Possibly related, we have observed that in the case when CPI data are included, and we use seasonal adjustment in our analysis, the IRF for PPI indices turn out to have an erratic pattern, and the IRF for CPI have in particular many cases a counter-intuitive positive sign. ${ }^{39}$ In the case when we restrict to PPI sectoral data in the FAVAR, a relevant observation

\footnotetext{
${ }^{38}$ See in particular Figure L and Figure $\mathrm{M}$ in Appendix D for aggregate and sector IRF and Figure N for scatter plots relating CIR and price change moments.

${ }^{39}$ This applies to the case using high-frequency identification.
} 
is that it is no more clear whether seasonal adjustment is appropriate, as PPI data display only a small degree of seasonality. For this reason, we provide results both with and without seasonal adjustment.

We carried out the analysis with PPI only both under the standard identification case, as well as in the case using the German 2-year bond yields, with HFI identification. Results are reported in Appendix Table P (in the not-seasonally-adjusted case) and Table Q (in the seasonallyadjusted case). Results in the not-seasonally-adjusted case are supportive both qualitatively and quantitatively of the sufficient statistics proposition: the coefficient on the Kurt/Freq ratio is positive and significant, and in the unconstrained regression Kurt and Freq have opposite signs, with roughly equal coefficients in absolute values (Table P). As in our baseline analysis, when the "long-run restriction" is imposed, the coefficients on the Kurt/Freq variable are much smaller reflecting that the dependent variable (the $C I R^{P}$ ) is much less volatile across sectors- , and actually more in line with the quantitative value predicted by theory (ie $1 / 6$ ). In the seasonally-adjusted case, presented in Appendix Table Q, results are supportive of the sufficient statistic proposition, when the long run restriction is not imposed. When that restriction is imposed however, results are not significant any more. This outcome is likely related to the fact that, in our data, jointly applying seasonal adjustment and imposing long-run restriction leads to virtually canceling all cross-sectional variations in the $C I R^{P}$. For that reason, while this particular case suggests some limitations to the robustness of the sufficient statistics result, we are not inclined to attach a disproportionate weight to that case.

\subsection{Removing Products with Sizeable Drifts in Price Levels}

The theoretical predictions of the model are derived under the assumption of small inflation. While this assumption is clearly fulfilled for the aggregate inflation rate in France on our sample period, a concern is that for some specific sectors it could not be the case. Table 1 provides some statistics on the average product-specific inflation rates in absolute values. Product-level inflation rates (taken in absolute value) are typically small as well: average and median inflation rates are about $1.5 \%$ per year whereas the third quartiles of inflation distribution are around $2 \%$. In this last 
robustness exercise, we remove all products for which we observe a non-small average inflation rate (in absolute values). In practice, we define small inflation rates as products with an average annual inflation lower than $5 \%$ in absolute values. ${ }^{40}$ For PPI products, only two products are removed, whereas for CPI 9 products are removed. For both PPI and CPI, results are reported in Appendix Table $\mathrm{R}$ and they are very consistent with the ones obtained in the baseline regressions even if coefficients are less significant in some specifications. ${ }^{41}$

\section{Conclusion}

Several recent theoretical analyses establish conditions under which the cumulative output response to a small monetary shock is summarized by the ratio of kurtosis over the frequency of price changes. ${ }^{42}$ This surprising result depends on several assumptions, and it should not be expected to fit the data perfectly given the stylized setups that give rise to it. Yet, as Leahy (2016) wrote: "it would be very nice to know if these statistics are at all informative. What is the correlation between these statistics and the real effect of a monetary policy shock? Do countries with greater kurtosis also have more potent monetary policy? What about industries? (p. 462)". This paper gathered data on the magnitudes involved by the theoretical proposition for a large number of French industries and constructed a theory-based test of this prediction in a low-inflation economy. We show that both the kurtosis and the frequency of price adjustment contain information about the non-neutrality of monetary shocks.

To accomplish this goal we first estimated sectoral responses to a monetary shock for about 120 manufacturing goods and 220 consumer products in France, using a Factor Augmented VAR. Our monetary shock was identified using several identification schemes and long-term restrictions to test the robustness of our findings. From this estimation, we have calculated for each product the cumulative impulse response of prices over long horizons. Then, using the micro data underlying

\footnotetext{
${ }^{40}$ Gagnon (2009), Nakamura et al. (2018) or Alvarez et al. (2019) for evidence on price rigidity in higher inflation rates, in Mexico, US and Argentina, they tend to show that when inflation is below 5\%, patterns of price rigidity (in particular, frequency of price changes) are rather unchanged.

${ }^{41}$ Using a threshold at $4 \%$ for defining 'small' vs 'large' inflation rates leads to similar results.

${ }^{42}$ See Alvarez, Le Bihan, and Lippi (2016); Alvarez, Lippi, and Paciello (2016); Alvarez, Lippi, and Oskolkov (2021); Baley and Blanco (2021).
} 
French CPI and PPI, we measured cross sectional moments of price changes corresponding to these sectors. Finally, we estimated several regressions relating the CIR of prices to the ratio Kurt/Freq to investigate empirically the predictions of the sufficient-statistic proposition.

For PPI products, the empirical results are fully in line with theory: the signs of the regression coefficients, and even the magnitude of the coefficients, correspond to the ones predicted by the theory. This result holds for a variety of FAVAR specifications and robustness tests. The coefficients associated with both the frequency and the kurtosis of price changes are statistically significant, have the expected sign, and we cannot reject that the size of the coefficient associated with frequency is the same in absolute value as the one associated with kurtosis, as theory predicts. In addition, "placebo" tests show that moments not suggested by the theory are not correlated with the CIR of prices.

For CPI products the results are mixed and are less robust than for PPI: the Kurt/Freq ratio has a positive and significant sign in several specifications, but this is less systematic than for PPI products. Similarly, we find that both the frequency and the kurtosis, when entering separately in the regressions, have the expected sign and size in most, but not all, specifications. One candidate explanation for the difference between the CPI and the PPI results might come from the fact that (even if we have attempted to remove observations affected by sales) the sufficient statistic result holds in a setting where the pricing strategy of firms features no seasonal sales or price plans, both of which are empirically more prevalent for CPI than for PPI. 


\section{References}

Alexandrov, Andrey. 2020. "The Effects of Trend Inflation on Aggregate Dynamics and Monetary Stabilization." Mimeo, University of Mannheim.

Altavilla, Carlo, Luca Brugnolini, Refet S. Gurkaynak, Roberto Motto, and Giuseppe Ragusa. 2019. "Measuring euro area monetary policy." Journal of Monetary Economics 108 (C):162179.

Alvarez, Fernando, Martin Beraja, Martin Gonzalez-Rozada, and Pablo Andres Neumeyer. 2019. "From Hyperinflation to Stable Prices: Argentinas Evidence on Menu Cost Models." The Quarterly Journal of Economics 143 (1):451-505.

Alvarez, Fernando E., Hervé Le Bihan, and Francesco Lippi. 2016. "The real effects of monetary shocks in sticky price models: a sufficient statistic approach." The American Economic Review 106 (10):2817-2851.

Alvarez, Fernando E. and Francesco Lippi. 2014. "Price setting with menu costs for multi product firms." Econometrica 82 (1):89-135.

. 2019. "The Analytic Theory of a Monetary Shock." EIEF Working Papers Series 1910, Einaudi Institute for Economics and Finance (EIEF).

Alvarez, Fernando E., Francesco Lippi, and Aleksei Oskolkov. 2021. "The Macroeconomics of Sticky Prices with Generalized Hazard Functions." Quarterly Journal of Economics forthcoming.

Alvarez, Fernando E., Francesco Lippi, and Luigi Paciello. 2016. "Monetary Shocks in Models with Inattentive Producers." Review of Economic Studies 83:421-459.

Alvarez, Fernando E., Francesco Lippi, and Panagiotis Souganidis. 2021. "Price Setting with Strategic Complementarities as Mean Field Games." Mimeo, University of Chicago.

Amiti, Mary, Oleg Itskhoki, and Jozef Konings. 2019. "International Shocks, Variable Markups, and Domestic Prices." The Review of Economic Studies 86 (6):2356-2402.

Anderson, James E. and J. Peter Neary. 2016. "Sufficient statistics for tariff reform when revenue matters." Journal of International Economics 98:150-159.

Andrade, Philippe and Filippo Ferroni. 2021. "Delphic and odyssean monetary policy shocks: Evidence from the euro area." Journal of Monetary Economics 117 (C):816-832.

Arkolakis, Costas, Arnaud Costinot, and Andres Rodriguez-Clare. 2012. "New Trade Models, Same Old Gains?" American Economic Review 102 (1):94-130.

Auer, Raphael, Ariel Burstein, and Sarah M. Lein. 2021. "Exchange Rates and Prices: Evidence from the 2015 Swiss Franc Appreciation." American Economic Review 111 (2):652-86.

Badel, Alejandro and Mark Huggett. 2017. "The sufficient statistic approach: Predicting the top of the Laffer curve." Journal of Monetary Economics 87 (C):1-12.

Baley, Isaac and Andres Blanco. 2021. "Aggregate Dynamics in Lumpy Economies." Econometrica 89 (3):1235-1264. 
Barro, Robert J. 1972. "A Theory of Monopolistic Price Adjustment." Review of Economic Studies 39 (1):17-26.

Baudry, L., H. Le Bihan, P. Sevestre, and S. Tarrieu. 2007. "What do Thirteen Million Price Records have to Say about Consumer Price Rigidity?" Oxford Bulletin of Economics and Statistics 69 (2):139-183.

Beck, Günter W. and Sarah M. Lein. 2020. "Price elasticities and demand-side real rigidities in micro data and in macro models." Journal of Monetary Economics 115:200-212.

Berardi, Nicoletta and Erwan Gautier. 2016. "Adjustments in Consumer Prices in France in Periods of Low Inflation." BdF Bulletin, Quarterly Selection of Articles 41.

Berardi, Nicoletta, Erwan Gautier, and Hervé Le Bihan. 2015. "More Facts about Prices: France Before and During the Great Recession." Journal of Money, Credit and Banking 47 (8):14651502 .

Berger, David and Joseph Vavra. 2018. "Dynamics of the U.S. price distribution." European Economic Review 103:60 - 82.

Bernanke, Ben S, Jean Boivin, and Piotr Eliasz. 2005. "Measuring the effects of monetary policy: a factor-augmented vector autoregressive (FAVAR) approach." The Quarterly Journal of Economics 120 (1):387-422.

Bils, Mark and Peter J. Klenow. 2004. "Some Evidence on the Importance of Sticky Prices." Journal of Political Economy 112 (5):947-985.

Boivin, Jean, Marc P. Giannoni, and Ilian Mihov. 2009. "Sticky Prices and Monetary Policy: Evidence from Disaggregated US Data." American Economic Review 99 (1):350-84.

Bonomo, Marco, Carlos Carvalho, Oleksiy Kryvtsov, Sigal Ribon, and Rodolfo Rigato. 2020. "Multi-Product Pricing: Theory and Evidence from Large Retailers in Israel." Staff Working Papers 20-12, Bank of Canada.

Bouakez, Hafedh, Emanuela Cardia, and Francisco J. Ruge-Murcia. 2009. "The Transmission Of Monetary Policy In A Multisector Economy." International Economic Review 50 (4):1243-1266.

Burstein, Ariel, Martin Eichenbaum, and Sergio Rebelo. 2005. "Large Devaluations and the Real Exchange Rate." Journal of Political Economy 113 (4):742-784.

Caballero, Ricardo J. 1989. "Time Dependent Rules, Aggregate Stickiness And Information Externalities." Discussion Papers 198911, Columbia University.

Caballero, Ricardo J. and Eduardo M. R. A. Engel. 1999. "Explaining Investment Dynamics in U.S. Manufacturing: A Generalized (S, s) Approach." Econometrica 67 (4):783-826.

Caballero, Ricardo J. and Eduardo M.R.A. Engel. 1993. "Heterogeneity and output fluctuations in a dynamic menu-cost economy." The Review of Economic Studies 60 (1):95.

. 2007. "Price stickiness in Ss models: New interpretations of old results." Journal of Monetary Economics 54 (Supplement):100-121. 
Calvo, Guillermo A. 1983. "Staggered prices in a utility-maximizing framework." Journal of Monetary Economics 12 (3):383-398.

Carvalho, Carlos. 2006. "Heterogeneity in Price Stickiness and the Real Effects of Monetary Shocks." The B.E. Journal of Macroeconomics 6 (3):1-58.

Carvalho, Carlos and Oleksiy Kryvtsov. 2018. "Price Selection." Staff Working Papers 18-44, Bank of Canada.

Carvalho, Carlos, Jae Won Lee, and Woong Yong Park. 2021. "Sectoral Price Facts in a StickyPrice Model." American Economic Journal: Macroeconomics 13 (1):216-256.

Cavallo, Alberto. 2018. "Scraped Data and Sticky Prices." The Review of Economics and Statistics $100(1): 105-119$.

. 2019. "More Amazon Effects: Online Competition and Pricing Behaviors." Jackson hole economic symposium conference proceedings, Federal Reserve Bank of Kansas City.

Cavallo, Alberto and Roberto Rigobon. 2016. "The Billion Prices Project: Using online prices for measurement and research ." Journal of Economic Perspectives 30 (2):151-178.

Chetty, Raj. 2009. "Sufficient Statistics for Welfare Analysis: A Bridge Between Structural and Reduced-Form Methods." Annual Review of Economics 1 (1):451-488.

Costain, James and Anton Nakov. 2011. "Distributional dynamics under smoothly state-dependent pricing." Journal of Monetary Economics 58 (6):646 - 665.

Costinot, Arnaud and Ivan Werning. 2018. "Robots, Trade, and Luddism: A Sufficient Statistic Approach to Optimal Technology Regulation." Working Paper 25103, National Bureau of Economic Research.

Dedola, Luca, Mark Strom Kristøffersen, and Gabriel Züllig. 2021. "The extensive and intensive margin of price adjustment to cost shocks: Evidence from Danish multiproduct firms." Mimeo, European Central Bank.

Dias, D.A., C. Robalo Marques, and J.M.C. Santos Silva. 2007. "Time- or state-dependent price setting rules? Evidence from micro data." European Economic Review 51 (7):1589 - 1613.

Dixit, Avinash. 1991. "Analytical Approximations in Models of Hysteresis." Review of Economic Studies 58 (1):141-51.

Dotsey, Michael and Alexander L. Wolman. 2020. "Investigating nonneutrality in a state-dependent pricing model with firm-level productivity shocks." International Economic Review 61 (1):159188.

Eichenbaum, Martin, Nir Jaimovich, and Sergio Rebelo. 2011. "Reference Prices, Costs, and Nominal Rigidities." American Economic Review 101 (1):234-62.

Eichenbaum, Martin S., Nir Jaimovich, Sergio Rebelo, and Josephine Smith. 2014. "How Frequent Are Small Price Changes?" American Economic Journal: Macroeconomics 6 (2):137-155. 
Fougere, Denis, Hervé Le Bihan, and Patrick Sevestre. 2007. "Heterogeneity in Consumer Price Stickiness." Journal of Business \&6 Economic Statistics 25 (3):247-264.

Gagnon, Etienne. 2009. "Price Setting During Low and High Inflation: Evidence from Mexico." Quarterly Journal of Economics 124 (3):1221-1263.

Gautier, Erwan. 2008. "The Behaviour of Producer Prices: Some Evidence from French PPI micro data." Empirical Economics 35:301-332.

Gautier, Erwan and Hervé Le Bihan. 2020. "Shocks vs Menu Costs: Patterns of Price Rigidity in an Estimated Multi-Sector Menu-Cost Model." Review of Economics and Statistics forthcoming.

Gautier, Erwan and Ronan Le Saout. 2015. "The Dynamics of Gasoline Prices: Evidence from Daily French Micro Data." Journal of Money, Credit and Banking 47 (6):1063-1089.

Gautier, Erwan, Magali Marx, and Paul Vertier. 2021. "How do Gasoline Prices Respond to a Cost Shock?" mimeo, Banque de France.

Gertler, Mark and Peter Karadi. 2015. "Monetary Policy Surprises, Credit Costs, and Economic Activity." American Economic Journal: Macroeconomics 7 (1):44-76.

Golosov, Mikhail and Robert E. Jr. Lucas. 2007. "Menu Costs and Phillips Curves." Journal of Political Economy 115:171-199.

Gorodnichenko, Yuriy and Michael Weber. 2016. "Are Sticky Prices Costly? Evidence from the Stock Market." American Economic Review 106 (1):165-99.

Harberger, Arnold C. 1964. "The Measurement of Waste." The American Economic Review $54(3): 58-76$.

Hong, Gee Hee, Matthew Klepacz, Ernesto Pasten, and Raphael Schoenle. 2020. "The Real Effects of Monetary Shocks: Evidence from Micro Pricing Moments." Working Papers Central Bank of Chile 875, Central Bank of Chile.

Imbs, Jean, Eric Jondeau, and Florian Pelgrin. 2011. "Sectoral Phillips curves and the aggregate Phillips curve." Journal of Monetary Economics 58 (4):328-344.

Jarocinski, Marek and Peter Karadi. 2020. "Deconstructing Monetary Policy Surprises: the role of Information Shocks." American Economic Journal: Macroeconomics 12 (2):1-43.

Klenow, Peter J. and Jonathan L. Willis. 2016. "Real Rigidities and Nominal Price Changes." Economica 83 (331):443-472.

Kleven, Henrik. 2020. "Sufficient Statistics Revisited." Working Paper 27242, National Bureau of Economic Research.

Koopmans, Tjalling C. 1953. "Identification problems in economic model construction." In Studies of Econometric Method, edited by TC Koopmans WC Hood. New York: Cowles Commission Res. Econ. Monogr. N. 14, pp. 27-48.

La'O, Jennifer and Alireza Tahbaz-Salehi. 2020. "Optimal Monetary Policy in Production Networks." Working Paper 27464, National Bureau of Economic Research. 
Leahy, John. 2016. Comment on "Are State and Time Dependent Models Really Different?", NBER Macroeconomics Annual 2016, Volume 31 Ch. 5. University of Chicago Press, 458-464.

Marschak, Jacob. 1953. "Economic Measurements for Policy and Prediction." In Studies of Econometric Method, edited by TC Koopmans WC Hood. New York: Cowles Commission Res. Econ. Monogr. N. 14, pp. 1-26.

Midrigan, Virgiliu. 2011. "Menu Costs, Multi-Product Firms, and Aggregate Fluctuations." Econometrica, 79 (4):1139-1180.

Nakamura, Emi and Jon Steinsson. 2008. "Five Facts about Prices: A Reevaluation of Menu Cost Models." The Quarterly Journal of Economics 123 (4):1415-1464.

. 2010. "Monetary Non-Neutrality in a Multisector Menu Cost Model." The Quarterly Journal of Economics 125 (3):961-1013.

Nakamura, Emi, Jon Steinsson, Patrick Sun, and Daniel Villar. 2018. "The Elusive Costs of Inflation: Price Dispersion during the U.S. Great Inflation." The Quarterly Journal of Economics 133 (4):1933-1980.

Petrella, Ivan, Emiliano Santoro, and Lasse de la Porte Simonsen. 2018. "Time-varying Price Flexibility and Inflation Dynamics." Discussion Paper 13027, CEPR.

Reis, Ricardo. 2006. "Inattentive producers." Review of Economic Studies 73 (3):793-821.

Schmieder, Johannes F. and Till von Wachter. 2016. "The Effects of Unemployment Insurance Benefits: New Evidence and Interpretation." Annual Review of Economics 8 (1):547-581.

Sheremirov, Viacheslav. 2019. "Price dispersion and inflation: New facts and theoretical implications." Journal of Monetary Economics .

Sheshinski, Eytan and Yoram Weiss. 1977. "Inflation and Costs of Price Adjustment." Review of Economic Studies 44 (2):287-303.

Stock, James H and Mark W Watson. 1999. "Forecasting inflation." Journal of Monetary Economics 44 (2):293-335.

—. 2002. "Macroeconomic forecasting using diffusion indexes." Journal of Business Er Economic Statistics 20 (2):147-162.

2016. "Dynamic factor models, factor-augmented vector autoregressions, and structural vector autoregressions in macroeconomics." In Handbook of macroeconomics, vol. 2. Elsevier, $415-525$.

Taylor, John B. 1980. "Aggregate Dynamics and Staggered Contracts." Journal of Political Economy 88 (1):1-23.

Vermeulen, Philip, Daniel A. Dias, Maarten Dossche, Erwan Gautier, Ignacio Hernando, Roberto Sabbatini, and Harald Stahl. 2012. "Price Setting in the Euro Area: Some Stylized Facts from Individual Producer Price Data." Journal of Money, Credit and Banking 44 (8):1631-1650. 


\section{Figures and Tables}

Figure 1: Sectoral Responses of PPI and CPI to a Contractionary Monetary Shock
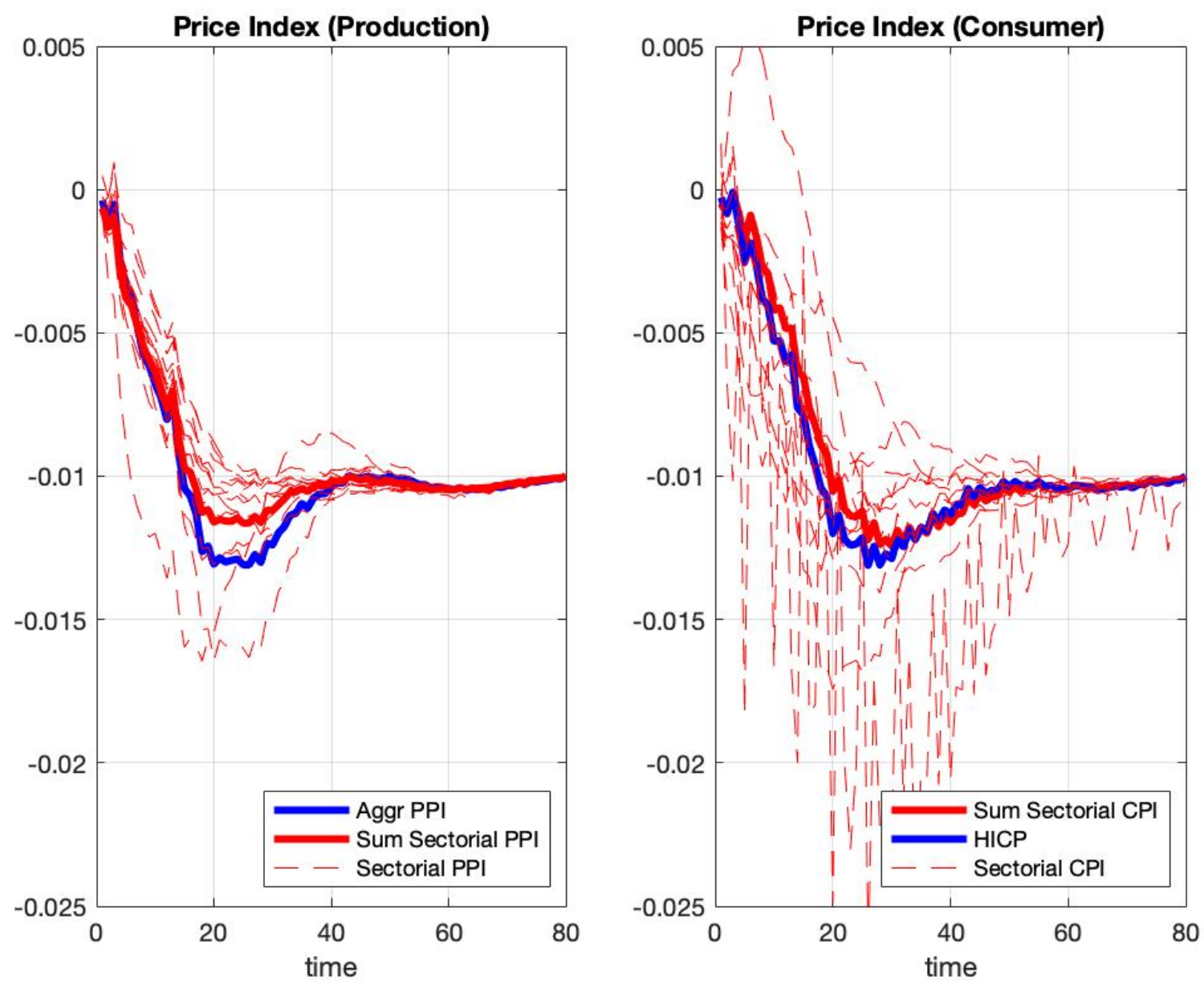

Note: y-axis: log points in deviation from the "steady state". Left panel sectoral IRFs of PPI, right panel sectoral IRFs of CPI. In both panel: blue line IRF of aggregate time series, dashed red lines sectoral IRFs, thick red line arithmetic average of sectoral IRFs. 
Figure 2: Cross-sector Distribution of Frequency and Kurtosis of Price Changes (CPI-PPI)

(a) Frequency

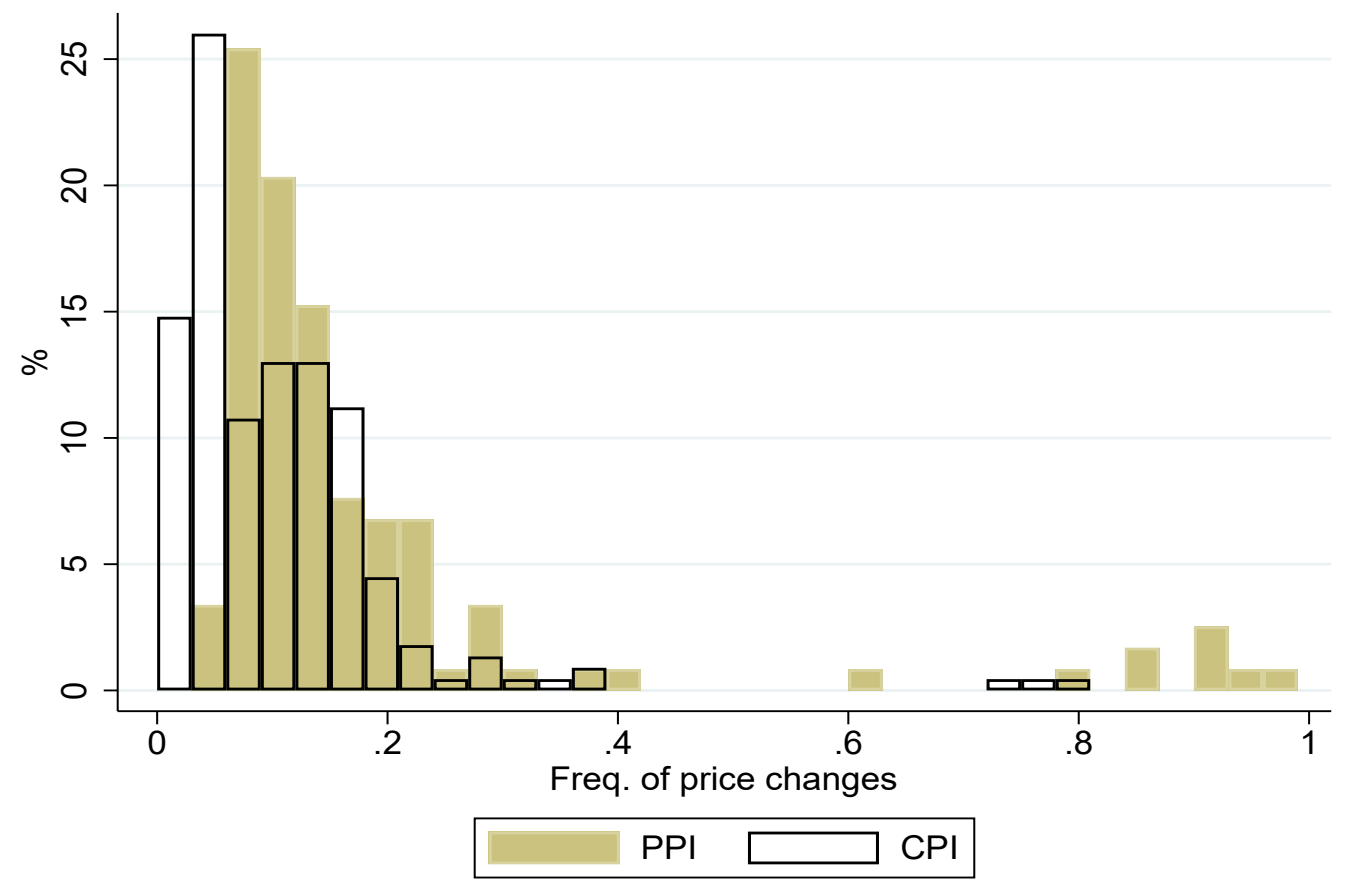

(b) Kurtosis

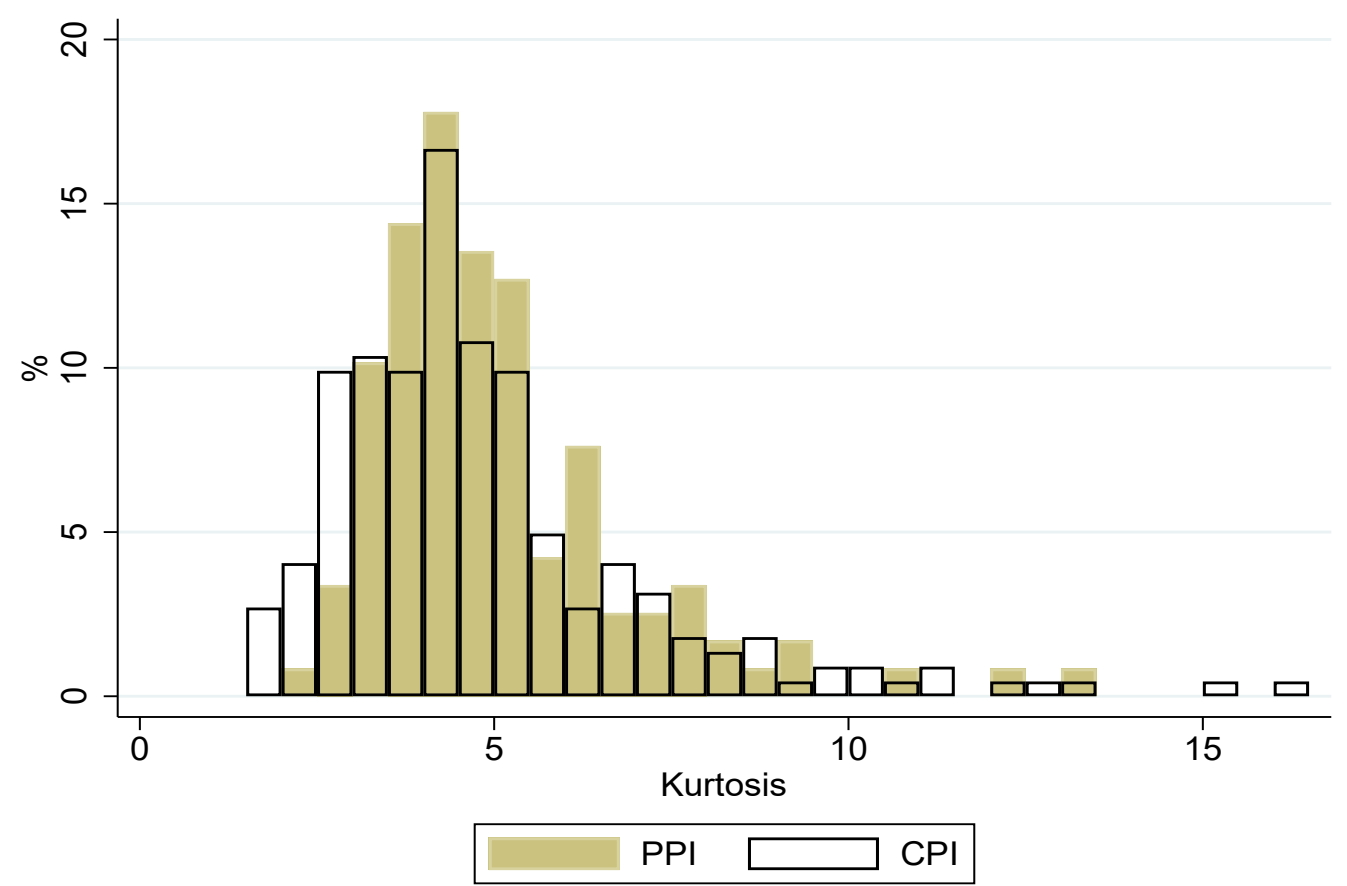

Note: histograms report the distribution of frequency and kurtosis separately for 118 PPI products and 227 CPI products. 
Figure 3: Correlation $C I R^{P}-\log$ ratio $\frac{\text { Kurt }}{\text { Freq }}$
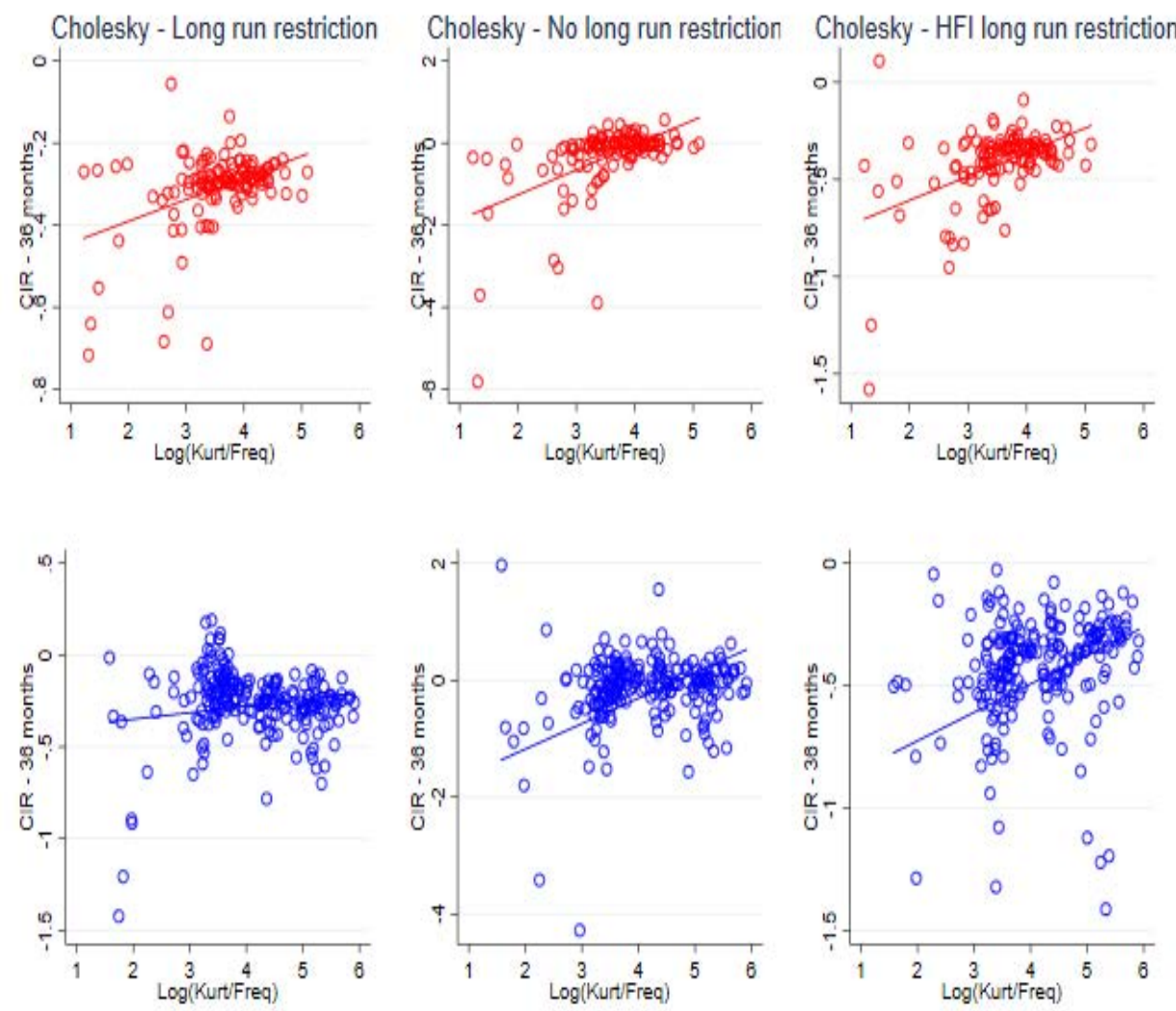

Note: the figure plots for each of the three FAVAR specifications the product-specific CIR (at the horizon 36 months) and the log of the ratio kurtosis over frequency of price changes. The top panel (red dots) reports results for PPI products whereas the bottom panel (blue dots) reports results for CPI products. 
Table 1: Micro Moments of Price Adjustments: Descriptive Statistics

\begin{tabular}{|c|c|c|c|c|c|c|}
\hline & $\begin{array}{c}\mathrm{Nb} \\
\text { products }\end{array}$ & Mean & Q1 & Q2 & Q3 & $\overline{\mathrm{SD}}$ \\
\hline \multicolumn{7}{|c|}{ Panel A: Frequency of price changes } \\
\hline CPI & 223 & 0.106 & 0.039 & 0.088 & 0.143 & 0.104 \\
\hline PPI & 118 & 0.190 & 0.086 & 0.123 & 0.185 & 0.208 \\
\hline \multicolumn{7}{|c|}{ Panel B: Kurtosis of non-zero price changes - with robustness } \\
\hline CPI - baseline & 223 & 5.039 & 3.355 & 4.434 & 5.652 & 2.952 \\
\hline PPI - baseline & 118 & 5.068 & 3.927 & 4.615 & 5.857 & 1.851 \\
\hline CPI - outlier $|\Delta p|<$ & 223 & 4.616 & 59 & 4.281 & 5.166 & 1.738 \\
\hline PPI - outlier $|\Delta p|<0.5 \%$ & 118 & 4.777 & 3.183 & 4.220 & 5.411 & 2.821 \\
\hline atlier $|\Delta p|>3$ & 223 & 6.273 & 0 & 71 & 7.207 & 316 \\
\hline PPI - outlier $|\Delta p|>25 \%$ & 118 & 7.805 & 5.532 & 6.956 & 9.042 & 3.952 \\
\hline CPI - & 223 & 3.424 & 2.227 & 3.194 & 3.834 & 2.013 \\
\hline PPI - hetero $(S=5)$ & 118 & 3.917 & 2.638 & 3.435 & 4.497 & 2.036 \\
\hline \multicolumn{7}{|c|}{ Panel C: Mean of non-zero price changes (percent) } \\
\hline CPI & 223 & 1.219 & 0.294 & 0.947 & 2.074 & 2.124 \\
\hline PPI & 118 & 0.793 & 0.204 & 0.722 & 1.405 & 0.906 \\
\hline \multicolumn{7}{|c|}{ Panel D: Standard deviation of non-zero price changes (percent) } \\
\hline CPI & 223 & 7.587 & 6.018 & 7.298 & 9.251 & 2.307 \\
\hline PPI & 118 & 4.149 & 3.606 & 4.134 & 4.674 & 0.872 \\
\hline \multicolumn{7}{|c|}{ Panel E: Skewness of non-zero price changes } \\
\hline CPI & 223 & -0.261 & -0.419 & -0.250 & -0.098 & 0.367 \\
\hline PPI & 118 & -0.274 & -0.559 & -0.275 & 0.028 & 0.444 \\
\hline \multicolumn{7}{|c|}{ Panel F: Average inflation (in percent, absolute values) } \\
\hline CPI & 223 & 1.883 & 0.663 & 1.531 & 2.368 & 2.123 \\
\hline PPI & 118 & 1.556 & 0.903 & 1.327 & 1.984 & 1.111 \\
\hline
\end{tabular}

Note: Calculations on CPI micro data are made over the period 1994-2019 (30 million of monthly price quotes). Prices of rents, cars, fresh food products, electricity and clothing goods are non-available or excluded. Price changes due to sales and promotions are excluded (using the INSEE flag). VAT change and euro-cash changeover periods are excluded as well. Calculation on PPI data are made over the period 1994-2005. We here report some descriptive statistics of the distribution of product-specific moments of price rigidity for PPI and CPI products (statistics are unweighted). 'Frequency' reports the ratio between the number of price changes and the total number of prices. 'Mean', 'Standard deviation', 'Skewness' and 'Kurtosis' are calculated on the distribution of non-zero log price changes, expressed in percentages. In our baseline calculations, we have excluded all price changes below than $0.1 \%$ in absolute values and larger than $25 \%$ in absolute values for CPI price changes and $15 \%$ for PPI price changes. Panel F provides statistics on the average product-specific inflation in absolute values over the period 2005-2019. "Hetero $(\mathrm{S}=5)$ " refers to the correction for heteroskedasticity presented in the Appendix. 
Table 2: Baseline OLS Regression Results : "Constrained" Specification

\begin{tabular}{|c|c|c|c|c|c|c|}
\hline \multirow[t]{2}{*}{$\begin{array}{l}\text { Identification } \\
\text { Long-run Restriction }\end{array}$} & \multicolumn{2}{|c|}{$\begin{array}{l}\text { Cholesky } \\
\text { Yes }\end{array}$} & \multicolumn{2}{|c|}{$\begin{array}{l}\text { Cholesky } \\
\text { No }\end{array}$} & \multicolumn{2}{|c|}{$\begin{array}{c}\text { High-Frequency IV } \\
\text { Yes }\end{array}$} \\
\hline & 24 months & 36 months & 24 months & 36 months & 24 months & 36 months \\
\hline \multicolumn{7}{|c|}{ PANEL A: PRODUCER PRICES } \\
\hline Kurt/Freq & $\begin{array}{c}0.0669^{* *} \\
(0.0326)\end{array}$ & $\begin{array}{c}0.0974^{* * *} \\
(0.0355)\end{array}$ & $\begin{array}{c}0.328^{* * * *} \\
(0.105)\end{array}$ & $\begin{array}{c}0.535^{* * *} \\
(0.162)\end{array}$ & $\begin{array}{l}0.192^{* * *} \\
(0.0614)\end{array}$ & $\begin{array}{c}0.242^{* * *} \\
(0.0801)\end{array}$ \\
\hline Constant & $\begin{array}{c}-20.57^{* * *} \\
(2.130)\end{array}$ & $\begin{array}{c}-35.16^{* * *} \\
(2.199)\end{array}$ & $\begin{array}{c}-22.84^{* * *} \\
(6.387)\end{array}$ & $\begin{array}{c}-38.95^{* * *} \\
(9.756)\end{array}$ & $\begin{array}{c}-34.27^{* * *} \\
(3.638)\end{array}$ & $\begin{array}{c}-52.21^{* * *} \\
(4.799)\end{array}$ \\
\hline Observations & 118 & 118 & 118 & 118 & 118 & 118 \\
\hline$R^{2}$ & 0.041 & 0.082 & 0.117 & 0.135 & 0.131 & 0.118 \\
\hline \multicolumn{7}{|c|}{ PANEL B: CONSUMER PRICES } \\
\hline Kurt/Freq & $\begin{array}{r}-0.0170 \\
(0.0165)\end{array}$ & $\begin{array}{c}-0.00245 \\
(0.0199)\end{array}$ & $\begin{array}{c}0.0739^{*} \\
(0.0423)\end{array}$ & $\begin{array}{l}0.150 * * \\
(0.0674)\end{array}$ & $\begin{array}{c}0.0495^{* *} \\
(0.0242)\end{array}$ & $\begin{array}{c}0.0720^{* *} \\
(0.0315)\end{array}$ \\
\hline Constant & $\begin{array}{c}-11.64^{* * *} \\
(2.809)\end{array}$ & $\begin{array}{c}-27.36^{* * *} \\
(3.285)\end{array}$ & $\begin{array}{c}-13.63^{*} \\
(6.954)\end{array}$ & $\begin{array}{c}-30.69 * * * \\
(11.02)\end{array}$ & $\begin{array}{c}-34.43^{* * *} \\
(3.434)\end{array}$ & $\begin{array}{c}-54.70^{* * *} \\
(4.419)\end{array}$ \\
\hline Observations & 223 & 223 & 223 & 223 & 223 & 223 \\
\hline$R^{2}$ & 0.004 & 0.000 & 0.014 & 0.023 & 0.019 & 0.024 \\
\hline
\end{tabular}

Note: this table reports results of OLS regressions (equation (10)) where the endogenous variable is the product-specific $C I R_{T}^{P_{j}}$ (expressed in \%) and RHS variable is the ratio Kurt/freq. Each observation corresponds to a disaggregate CPI or PPI product. For CPI, the level of disaggregation is 5 digit-level of the ECOICOP classification (ie. '01.1.1.1') whereas for PPI, the product level is the 4-digit level of the NACE rev2 classification of sectors. PPI covers the manufacturing sectors whereas CPI covers about $60 \%$ of the whole French CPI (main products excluded are rents, cars, utilities like electricity). Robust standard errors are reported in parentheses. $* * * \mathrm{p}<0.01,{ }^{* *} \mathrm{p}<0.05,{ }^{*} \mathrm{p}<0.1$ 
Table 3: Regression Results - "Unconstrained" Specification

\begin{tabular}{|c|c|c|c|c|c|c|}
\hline \multirow[t]{2}{*}{$\begin{array}{l}\text { Identification } \\
\text { Long-run Restriction }\end{array}$} & \multicolumn{2}{|c|}{$\begin{array}{l}\text { Cholesky } \\
\text { Yes }\end{array}$} & \multicolumn{2}{|c|}{$\begin{array}{l}\text { Cholesky } \\
\text { No }\end{array}$} & \multicolumn{2}{|c|}{$\begin{array}{c}\text { High-Frequency IV } \\
\text { Yes }\end{array}$} \\
\hline & 24 months & 36 months & 24 months & 36 months & 24 months & 36 months \\
\hline \multicolumn{7}{|c|}{ PANEL A: PRODUCER PRICES } \\
\hline Freq/F & $\begin{array}{l}-2.501^{*} \\
(1.279)\end{array}$ & $\begin{array}{c}-3.153^{* *} \\
(1.314)\end{array}$ & $\begin{array}{c}-11.25 * * * \\
(4.232)\end{array}$ & $\begin{array}{c}-17.79 * * * \\
(6.641)\end{array}$ & $\begin{array}{c}-6.004^{* *} \\
(2.776)\end{array}$ & $\begin{array}{c}-7.239^{*} \\
(3.761)\end{array}$ \\
\hline Kurt $/ \bar{K}$ & $\begin{array}{l}3.663^{*} \\
(1.897)\end{array}$ & $\begin{array}{c}4.665 * * \\
(1.995)\end{array}$ & $\begin{array}{c}13.72^{* *} \\
(5.547)\end{array}$ & $\begin{array}{c}21.49^{* *} \\
(8.370)\end{array}$ & $\begin{array}{c}6.662^{* *} \\
(3.100)\end{array}$ & $\begin{array}{l}7.922^{*} \\
(4.010)\end{array}$ \\
\hline Constant & $\begin{array}{c}-18.82^{* * *} \\
(2.208)\end{array}$ & $\begin{array}{c}-32.42^{* * *} \\
(2.166)\end{array}$ & $\begin{array}{c}-11.00^{*} \\
(6.054)\end{array}$ & $\begin{array}{c}-19.33^{* *} \\
(8.855)\end{array}$ & $\begin{array}{c}-26.56^{* * *} \\
(3.011)\end{array}$ & $\begin{array}{c}-42.36^{* * *} \\
(3.960)\end{array}$ \\
\hline Observations & 118 & 118 & 118 & 118 & 118 & 118 \\
\hline$R^{2}$ & 0.106 & 0.161 & 0.240 & 0.259 & 0.217 & 0.179 \\
\hline \multicolumn{7}{|c|}{ PANEL B: CONSUMER PRICES } \\
\hline Freq $/ \bar{F}$ & $\begin{array}{l}-4.920^{*} \\
(2.809)\end{array}$ & $\begin{array}{c}-8.540^{* *} \\
(3.331)\end{array}$ & $\begin{array}{c}-34.84^{* * *} \\
(8.857)\end{array}$ & $\begin{array}{c}-58.62^{* * *} \\
(13.71)\end{array}$ & $\begin{array}{c}-16.36^{* * *} \\
(3.894)\end{array}$ & $\begin{array}{c}-21.30^{* * *} \\
(4.812)\end{array}$ \\
\hline Kurt $/ \bar{K}$ & $\begin{array}{l}4.359^{*} \\
(2.328)\end{array}$ & $\begin{array}{c}5.657^{* *} \\
(2.594)\end{array}$ & $\begin{array}{l}4.276 \\
(2.909)\end{array}$ & $\begin{array}{l}5.519 \\
(4.518)\end{array}$ & $\begin{array}{c}7.132^{* * *} \\
(2.201)\end{array}$ & $\begin{array}{l}9.175^{* * *} \\
(2.806)\end{array}$ \\
\hline Constant & $\begin{array}{c}-12.61^{* * *} \\
(3.684)\end{array}$ & $\begin{array}{c}-24.70 * * * \\
(4.267)\end{array}$ & $\begin{array}{c}23.60^{* * *} \\
(8.469)\end{array}$ & $\begin{array}{c}35.92^{* * *} \\
(13.12)\end{array}$ & $\begin{array}{c}-20.74^{* * *} \\
(4.907)\end{array}$ & $\begin{array}{c}-36.08 * * * \\
(6.274)\end{array}$ \\
\hline Observations & 223 & 223 & 223 & 223 & 223 & 223 \\
\hline$R^{2}$ & 0.065 & 0.132 & 0.477 & 0.529 & 0.350 & 0.342 \\
\hline
\end{tabular}

Note: this table reports results of OLS regressions (equation (11)) where the endogenous variable is the productspecific $C I R_{T}^{P_{j}}$ (expressed in \%) and RHS variables are the ratio of the product-level frequency over its average Freq $/ \bar{F}$ and the ratio of the product-level kurtosis over its average Kurt $/ \bar{K}$. Robust standard errors are reported in parentheses. ${ }^{* * *} \mathrm{p}<0.01,{ }^{* *} \mathrm{p}<0.05,{ }^{*} \mathrm{p}<0.1$ 
Table 4: Regression Results - Placebo Specification

$\begin{array}{lccc}\text { Identification } & \text { Cholesky } & \text { Cholesky } & \text { High-Frequency IV } \\ \text { Long-run Restriction } & \text { Yes } & \text { No } & \text { Yes }\end{array}$

24 months 36 months $\mid 24$ months 36 months $\mid 24$ months 36 months

\begin{tabular}{|c|c|c|c|c|c|c|}
\hline \multicolumn{7}{|c|}{ PANEL A: PRODUCER PRICES } \\
\hline Kurt/Freq & $\begin{array}{c}0.0849^{*} \\
(0.0477)\end{array}$ & $\begin{array}{c}0.110 * * \\
(0.0488)\end{array}$ & $\begin{array}{c}0.340^{* *} \\
(0.135)\end{array}$ & $\begin{array}{c}0.538 * * \\
(0.205)\end{array}$ & $\begin{array}{c}0.168^{* *} \\
(0.0750)\end{array}$ & $\begin{array}{c}0.202^{* *} \\
(0.0989)\end{array}$ \\
\hline Mean & $\begin{array}{l}-0.418 \\
(0.905)\end{array}$ & $\begin{array}{l}-0.479 \\
(1.000)\end{array}$ & $\begin{array}{l}-2.954 \\
(2.527)\end{array}$ & $\begin{array}{l}-4.724 \\
(3.925)\end{array}$ & $\begin{array}{l}-1.212 \\
(1.432)\end{array}$ & $\begin{array}{l}-1.408 \\
(1.857)\end{array}$ \\
\hline Skewness & $\begin{array}{l}1.759 \\
(3.434)\end{array}$ & $\begin{array}{l}1.006 \\
(3.100)\end{array}$ & $\begin{array}{l}-2.385 \\
(7.222)\end{array}$ & $\begin{array}{l}-5.930 \\
(10.02)\end{array}$ & $\begin{array}{l}-4.613 \\
(2.783)\end{array}$ & $\begin{array}{c}-6.889^{*} \\
(4.109)\end{array}$ \\
\hline Standard dev & $\begin{array}{l}-0.940 \\
(1.016)\end{array}$ & $\begin{array}{l}-0.749 \\
(1.083)\end{array}$ & $\begin{array}{l}-2.054 \\
(3.348)\end{array}$ & $\begin{array}{l}-2.614 \\
(5.166)\end{array}$ & $\begin{array}{l}0.219 \\
(1.964)\end{array}$ & $\begin{array}{l}0.726 \\
(2.535)\end{array}$ \\
\hline Constant & $\begin{array}{c}-16.65^{* * *} \\
(4.669)\end{array}$ & $\begin{array}{c}-31.95^{* * *} \\
(4.791)\end{array}$ & $\begin{array}{l}-13.15 \\
(12.69)\end{array}$ & $\begin{array}{l}-26.11 \\
(19.14)\end{array}$ & $\begin{array}{c}-34.44^{* * *} \\
(7.221)\end{array}$ & $\begin{array}{c}-54.26^{* * *} \\
(9.552)\end{array}$ \\
\hline Observations & 118 & 118 & 118 & 118 & 118 & 118 \\
\hline$R^{2}$ & 0.054 & 0.089 & 0.125 & 0.142 & 0.140 & 0.130 \\
\hline \multicolumn{7}{|c|}{ PANEL B: CONSUMER PRICES } \\
\hline Kurt/Freq & $\begin{array}{c}-0.0529 * * \\
(0.0206)\end{array}$ & $\begin{array}{l}-0.0308 \\
(0.0253)\end{array}$ & $\begin{array}{c}0.0922 \\
(0.0580)\end{array}$ & $\begin{array}{c}0.212^{* *} \\
(0.0929)\end{array}$ & $\begin{array}{c}0.0585^{*} \\
(0.0348)\end{array}$ & $\begin{array}{c}0.0923 * * \\
(0.0455)\end{array}$ \\
\hline Mean & $\begin{array}{c}1.636 * * \\
(0.755)\end{array}$ & $\begin{array}{l}1.498^{*} \\
(0.826)\end{array}$ & $\begin{array}{l}0.911 \\
(1.223)\end{array}$ & $\begin{array}{l}0.284 \\
(1.981)\end{array}$ & $\begin{array}{l}0.550 \\
(0.864)\end{array}$ & $\begin{array}{l}0.380 \\
(1.159)\end{array}$ \\
\hline Skewnes & $\begin{array}{l}2.109 \\
(3.699)\end{array}$ & $\begin{array}{l}5.033 \\
(4.102)\end{array}$ & $\begin{array}{c}10.83 \\
(8.134)\end{array}$ & $\begin{array}{l}19.63 \\
(13.28)\end{array}$ & $\begin{array}{c}11.30^{* * *} \\
(4.227)\end{array}$ & $\begin{array}{c}15.52^{* * *} \\
(5.603)\end{array}$ \\
\hline Standard dev. & $\begin{array}{c}-1.992^{* *} \\
(0.860)\end{array}$ & $\begin{array}{c}-1.732^{*} \\
(1.044)\end{array}$ & $\begin{array}{l}2.204 \\
(2.358)\end{array}$ & $\begin{array}{l}5.291 \\
(3.684)\end{array}$ & $\begin{array}{l}0.332 \\
(1.166)\end{array}$ & $\begin{array}{l}0.795 \\
(1.486)\end{array}$ \\
\hline Constant & $\begin{array}{l}5.271 \\
(7.708)\end{array}$ & $\begin{array}{l}-12.17 \\
(9.376)\end{array}$ & $\begin{array}{l}-30.29 \\
(23.82)\end{array}$ & $\begin{array}{c}-71.69^{*} \\
(37.61)\end{array}$ & $\begin{array}{c}-35.49 * * * \\
(11.33)\end{array}$ & $\begin{array}{c}-58.97^{* * *} \\
(14.45)\end{array}$ \\
\hline $\begin{array}{l}\text { Observations } \\
R^{2}\end{array}$ & $\begin{array}{c}223 \\
0.067\end{array}$ & $\begin{array}{c}223 \\
0.038\end{array}$ & $\begin{array}{c}223 \\
0.027\end{array}$ & $\begin{array}{c}223 \\
0.050\end{array}$ & $\begin{array}{c}223 \\
0.036\end{array}$ & $\begin{array}{c}223 \\
0.045\end{array}$ \\
\hline
\end{tabular}

Note: this table reports results of OLS regressions ( equation (10)) where the endogenous variable is the productspecific $C I R_{T}^{P_{j}}$ (expressed in \%) and RHS variables include the product-specific ratio Kurt/freq but also three other moments of the product-specific price change distribution: the average price change Mean, the skewness of price changes Skewness, and the standard deviation of price changes StandardDev.. Robust standard errors are reported in parentheses. ${ }^{* * *} \mathrm{p}<0.01,{ }^{* *} \mathrm{p}<0.05,{ }^{*} \mathrm{p}<0.1$ 